\title{
Theory of Sonochemistry
}

Sukhvir Kaur Bhangu and Muthupandian Ashokkumar* School of Chemistry, University of Melbourne, Victoria 3010, Australia

*masho@unimelb.edu.au

\section{Table of Contents}

\section{Theory of Sonochemistry}

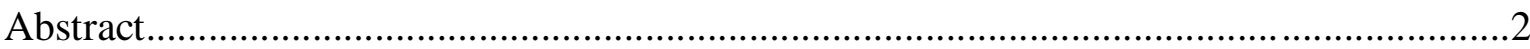

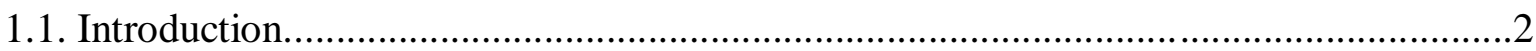

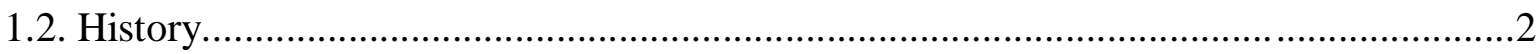

1.3. Acoustic cavitation

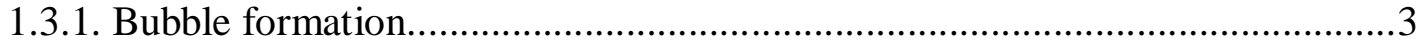

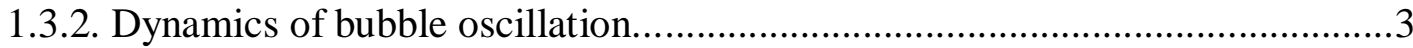

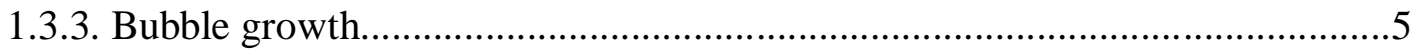

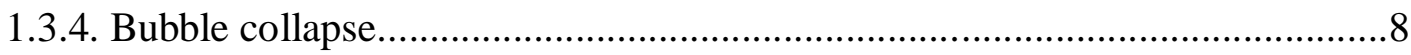

1.4. Physical \& chemical effects generated by acoustic cavitation.....................................14

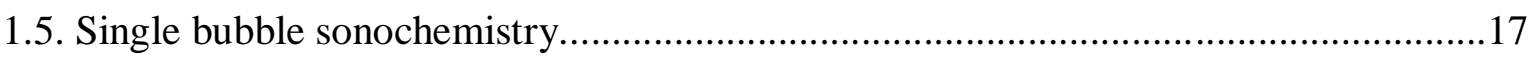

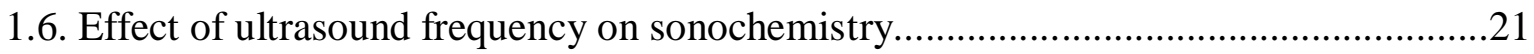

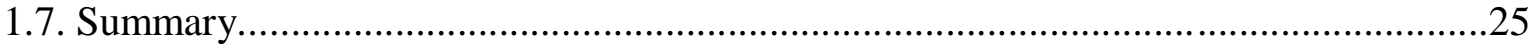

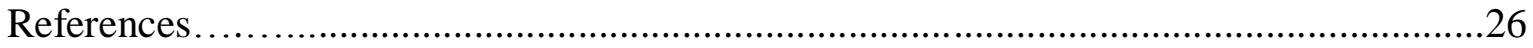




\begin{abstract}
Sonochemistry refers to ultrasound-initiated chemical processes in liquids. The interaction between bubbles and sound energy in liquids results in acoustic cavitation. This chapter presents the fundamental aspects of acoustic cavitation and theoretical aspects behind sonochemistry such as dynamics of bubble oscillation, rectified diffusion process that is responsible for the growth of cavitation bubbles, near adiabatic collapse of cavitation bubbles resulting in extreme reaction conditions and several chemical species generated within collapsing bubbles that are responsible for various redox reactions. Specifically, a detailed discussion on single bubble sonochemistry is provided.
\end{abstract}

\title{
1.1. Introduction
}

Ultrasound refers to sound waves beyond the frequency that can be detected by the human ear. Sound waves with a frequency of $>20 \mathrm{kHz}$ fall under this category. Ultrasound is divided into three main regions: low frequency $(20-100 \mathrm{kHz})$, intermediate frequency $(100 \mathrm{kHz}-1$ $\mathrm{MHz})$ and high frequency $(1-10 \mathrm{MHz})[1]$; however, intermediate range is also sometime referred as high frequency. Ultrasound interacts with gas bubbles in liquids generating chemical reactions and strong physical forces that could be used for various processing applications and for promoting chemical reactions. The driving force for the generation of chemical and physical forces is acoustic cavitation, which generates extreme temperatures and pressures. The consequences of these extreme conditions generated include radical generation, light emission - sonoluminescence (SL), shock waves, microjets, microstreaming, shear forces and turbulence [1]. Due to these strong physical and chemical effects, various applications of acoustic cavitation have been developed for its commercial usage including wastewater treatment [2] and the formation of protein microbubbles which can be used for flavour encapsulation and drug delivery [3].

\subsection{History}

Cavitation phenomenon was first reported by Thornycroft and Barnaby [4] in 1895. In 1917, Rayleigh published the first mathematical model describing cavitation event in an incompressible liquid [5]. In 1930's Brohult [6] and other groups discovered that sonication can be used for the degradation of bio- and synthetic polymers. In 1935 Frenzel and Schulze [7] reported for the first time that light emission occurred in water when exposed to intense ultrasound. In 1944 Weiss [8] observed that the sonication of water leads to the generation of hydrogen and hydroxyl radicals and later in 1956, Parke and Taylor [9] provided the first experimental evidence for the formation of $\mathrm{OH}$ radicals in aqueous solutions. The first observations on chemical reactions in organic solutions were made in the early 1950s. It was found that methanol solutions containing diphenylpicryl hydracyl were decolourised, indicating the formation of free radicals [10]. Also, the first computer calculations modelling a cavitation bubble was published by Neppiras and Noltingk [11] in 1950. Makino et al. [12] used spin trapping agents and electron spin resonance measurements to verify the formation of $\mathrm{H}$ and $\mathrm{OH}$ radicals during the sonication of water. It was reported in 1987 by Henglein [13] that over $80 \%$ of primary radicals originally generated in the hotspot recombine to produce water molecules. Since 1930s, acoustic cavitation has gained popularity as it can be used for the enhancement of chemical reactions, emulsification of oils, degradation of chemical and biological pollutants, etc. 
A number of books, review articles and book chapters have been published on acoustic cavitation and its applications are available in the literature. Fundamentals of an acoustic bubble have been discussed in detail by Leighton[14] in his book 'The Acoustic Bubble'. Mason and Lorimer [15-17] have published various review articles and books dealing with different aspects of ultrasound such as theory of sonochemistry, applications of ultrasound in food technology, uses of ultrasound in chemical synthesis, physical aspects of sonochemistry. A review by Leong et al. focuses on the fundamentals of ultrasound-induced physical processes such as transient and stable cavitation, rectified diffusion, coalescence and sonoluminescence [18]. The current review provides an overview of various fundamental processes of acoustic cavitation with a particular emphasis on single bubble sonochemistry.

\subsection{Acoustic cavitation}

\subsubsection{Bubble formation}

Acoustic cavitation is the phenomenon of formation, growth and violet collapse induced by the pressure fluctuations generated by sound waves in a liquid medium. If the intensity of ultrasound is enough to overcome the tensile strength of the medium, there occurs a point where intermolecular forces are not able to hold the molecular structure together. This point leads to the formation of a cavity in the medium. A large amount of energy is required to create a void or cavity. Equation 1 can be used to calculate the critical pressure $\left(\mathrm{P}_{\mathrm{B}}\right)$ required to create a cavity of radius, $\mathrm{R}_{\mathrm{e}}$.

$$
P_{B} \sim P_{h}+\frac{0.77 \sigma}{R e}
$$

$\sigma$ is surface tension of the liquid and $\mathrm{P}_{\mathrm{h}}$ is hydrostatic pressure (could be approximated to atmospheric pressure under normal experimental conditions). The equation is valid when $2 \sigma R_{e} \ll P_{h}[19]$. However, free gas bubbles and gas molecules trapped in solid impurities are inherently present in liquids, which can act as nuclei for cavitation. Hence, the actual pressure required is far less for cavitation to occur. Hence, in practical terms, acoustic cavitation refers to the growth of pre-existing gas nuclei followed by the collapse of "grown" bubbles.

There are different mechanisms associated with the formation of bubbles [14]. Firstly, gas molecules trapped in crevices of the container walls, motes or on hydrophobic dust particles [20] can act as bubble source. Harvey's crevice model depicts how an air bubble can be nucleated from cervices. A gas pocket, trapped in a crevice, responds to alternating compression and the rarefaction cycles of the applied ultrasound. The gas pocket expands considerably during the negative pressure cycle. When the gas pocket grows sufficiently it gets detached from crevice leading to the formation of free a gas bubble in the liquid [21]. Dissolved gas in the liquid then fills the residual gas cavity under applied sound field and the cycle is repeated. The second mechanism is based on the skin model where inherently present bubble nuclei are stabilized against dissolution when their surface is completely covered with organic materials or surfactants [22]. It has also been suggested that such bubbles can be stabilized by hydrophobic impurities present in a liquid. These bubbles tend to grow in an acoustic field by coalescence or rectified diffusion [23, 24]. Recently Yasui et al. have introduced the dynamic equilibrium model for the stabilization of the bubbles covered with 
the hydrophobic materials [25]. A chemical potential gradient that exists near the edge of hydrophobic material generates a dynamic equilibrium state [25]. Other mechanism for the nucleation is fragmentation of the active cavitation bubbles [26]. The shape instability of a bubble which is mostly induced by asymmetric collapse leads to the fragmentation of the bubble into several daughter bubbles which then act as new nuclei for cavitation [27-30].

Before discussing the growth of an acoustic cavitation bubble, the fundamental equations used to study the motion of bubbles in an acoustic field have been discussed in the following section.

\subsubsection{Dynamics of bubble oscillation}

This section focuses on the oscillation dynamics of a gas bubble in an acoustic field. Further details on this can be found in the book "The Acoustic bubble" by Leighton [14]. The Rayleigh-Plesset equation is used to examine the dynamics of a bubble oscillating at finite amplitudes $[5,14,31]$. The equation describes the motion of a spherical bubble to a timevarying pressure field in an incompressible liquid. When time $\mathrm{t}<0$, a bubble of radius $R_{0}$ is at rest in an incompressible viscous liquid and hydrostatic pressure is $p_{0}$ which is constant. However, at $\mathrm{t}>0$ pressure $p_{t}$ varies with time and is superimposed on $p_{0}$, so that the pressure of liquid at certain point from the bubble, $p_{\infty}=p_{0}+p_{t}$ which results in a change of bubble radius to some new value $R_{t}$. During this process, the liquid shell around the bubble acquires kinetic energy of

$\frac{1}{2} \rho \int_{R}^{\infty} \dot{r}^{2} 4 \pi r^{2} d r$

Equation 1

Where shell at radius $r$ has thickness $d r$, mass $=4 \pi r^{2} \rho d r$ ( $\rho=$ density of liquid) and $\dot{r}$ is speed.

Using the liquid incompressibility condition, $\dot{r} / \dot{R}=R^{2} / r^{2}$ (where $\mathrm{R}$ is radius of bubble when contracted, $\dot{R}$ is the wall velocity) Equation 1 can be integrated to give $2 \pi \rho R^{3} \dot{R}^{2}$. Equating this to the difference between the work done at certain point from the bubble by $p_{\infty}$ and the work done by the pressure $p_{\mathrm{L}}$ in the liquid outside the bubble wall gives

$\int_{R_{0}}^{R}\left(p_{L}-p_{\infty}\right) 4 \pi R^{2} d R=2 \pi R^{3} \dot{R}^{2}$

Equation 2

Equation (4) is obtained after differentiating Equation (2) w.r.t $R$, noting that

$$
\begin{gathered}
\frac{\partial(\dot{R})^{2}}{\partial R}=\frac{1}{\dot{R}} \frac{\left(\dot{R}^{2}\right)}{\partial t}=2 \ddot{R} \\
\frac{p_{L}-p_{\infty}}{\rho}=\frac{3 \dot{R}^{2}}{2}+R \ddot{R}
\end{gathered}
$$

Equation 3

Equation 4 
Where $\dot{R}$ is the velocity of the cavity, $\ddot{R}$ is the acceleration of the cavity

The liquid pressure $p_{L}$ for a pulsating bubble containing gas and vapour is given as,

$$
p_{L}=\left(p_{0}+\frac{2 \sigma}{R_{0}}-p_{v}\right)\left(\frac{R_{0}}{R}\right)^{3 \gamma}+p_{v}-\frac{2 \sigma}{R}
$$

Where, $p_{v}$ is vapour pressure of the liquid, $\sigma$ is surface tension, $p_{0}$ is the ambient pressure, $\gamma$ is the ratio of specific heat of gas at constant pressure to that of constant volume.

Substituting $p_{L}$ from Equation 5 and $p_{\infty}=p_{0}+p t$ into Equation 3,

$$
R \ddot{R}+\frac{3 \dot{R}^{2}}{2}=\frac{1}{\rho}\left\{\left(p_{0}+\frac{2 \sigma}{R_{0}}-p_{v}\right)\left(\frac{R_{0}}{R}\right)^{3 \gamma}+p_{v}-\frac{2 \sigma}{R}-p_{0}-p t\right\}
$$

Equation 6

The effect of viscosity on the above equation was considered by Poritsy [32], who found that viscosity effects arises through boundary conditions and not through the Navier-Stokes equation and obtained Equation 7.

$$
\ddot{R} R+\frac{3 \dot{R}^{2}}{2}=\frac{1}{\sigma}\left\{\left(p_{0}+\frac{2 \sigma}{R_{0}}-p_{v}\right)\left(\frac{R_{0}}{R}\right)^{3 \gamma}+p_{v}-\frac{2 \sigma}{R}-\frac{4 \eta \dot{R}}{R}-p_{0}-P(t)\right\} \text { Equation } 7
$$

where $\eta$ is the viscosity of the liquid.

Equations 4, 6, and 7 are commonly known as 'Rayleigh-Plesset' equations and they indicate that the motion of a bubble under the acoustic field is non-linear.

A spherical bubble is subjected to the time varying pressure of amplitude $p_{A}$ and circular frequency $\omega$. Therefore,

$$
p t=-p_{A} \sin (\omega t)
$$

Equation 8

Substituting Equation (8) into Equation (7) gives:

$$
\ddot{R} R+\frac{3 \dot{R}^{2}}{2}=\frac{1}{\sigma}\left\{\left(p_{0}+\frac{2 \sigma}{R_{0}}-p_{v}\right)\left(\frac{R_{0}}{R}\right)^{3 \gamma}+p_{v}-\frac{2 \sigma}{R}-\frac{4 \eta \dot{R}}{R}-p_{0}+p_{A} \sin (\omega t)\right\}
$$

Equation 9

Equation 9 is the fundamental equation used to describe the bubble motion at different frequencies. Over the past few decades the equation has been extended significantly to 
account for damping effects, solution compressibility, condensation, non-linear evaporation etc. $[33,34]$.

\subsubsection{Bubble growth}

Bubbles inherently present in liquids tend to grow to a critical size (which is influenced by several parameters such as acoustic pressure, ultrasonic power and frequency, viscosity of medium, etc.) in an ultrasonic field. The ultrasound driven growth is due to "rectified diffusion" which is defined as "the slow growth of pulsating gas bubble due to an average flow of mass (dissolved gases and solvent vapour) into the bubble as a function of time. Crum [24] explained this "rectification of mass" in terms of two effects, viz., "area effect" and "shell effect", schematically shown in Figure 1.

A gas bubble trapped in a liquid tends to expand when the surrounding liquid experiences negative pressure of the sound wave. At this stage, the low internal pressure of the bubble results in the evaporation of solvent molecules and diffusion of dissolved gases into the bubble from the surrounding liquid. Therefore, the rarefaction cycle leads to "intake" of gas and vapour molecules. The bubble is compressed when the surrounding liquid experiences the positive pressure (compression cycle) of the sound wave. At this stage, the internal pressure of the bubble is high, which leads to the expulsion of the gas/vapour molecules from the bubble into the surrounding liquid. Thus, the compression cycle leads to the "loss" of bubble mass. Since the bubble collapse is relatively fast and less surface area is available for mass transport, the amount of material that diffuses out of the bubble during compression cycle is always less that that diffuses into the bubble during expansion cycle leading to the net growth of bubble. This is known as the area effect.

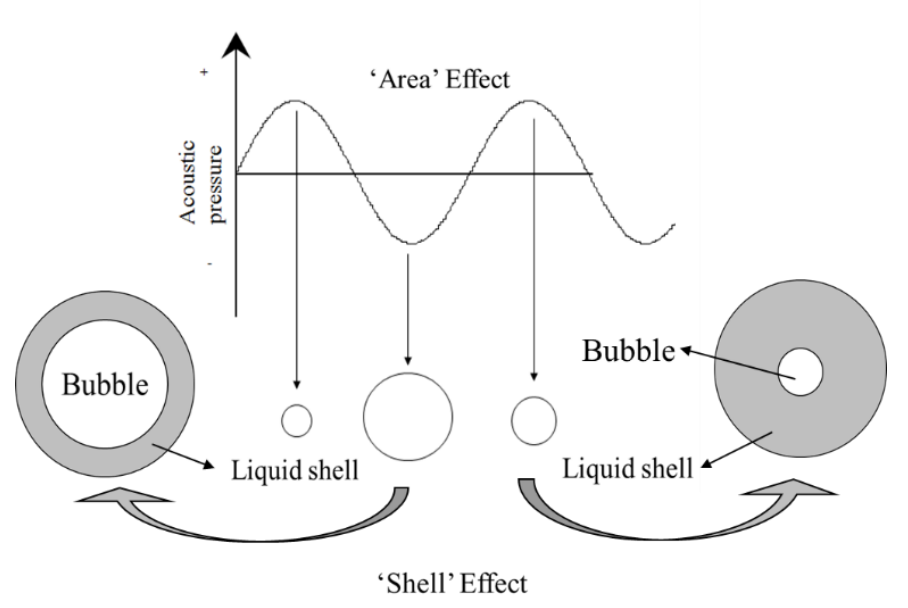

Figure 1: Schematic description of the growth of a bubble in an acoustic field by "area" and "shell" effects. (Adapted from [35]).

A change in the surface area of the bubble alone, however, is not sufficient to explain rectified diffusion. The concentration of dissolved gases and thickness of liquid shell around the bubble change during expansion and rarefaction cycle. During the compression half cycle, the bubble contracts and the shell thickness increases leading to a decrease in the concentration of gases within the shell. This generates a concentration difference between the gas at the interface and bulk. The rate of diffusion of gas in a liquid is proportional to the 
gradient of the concentration of the dissolved gas. However, the gas concentration gradient lowers as the shell thickness increases, which lowers the mass transfer of the gas coming out of the bubble. When the bubble is in its expanded state, the liquid shell becomes thinner (relative to the size of the bubble) with a relatively higher gas concentration. Since the gas concentration inside the bubble is lower, material diffuses into the bubble from the surrounding liquid shell. Two factors i.e. gas concentration at the bubble wall and the shell thickness, work together when the bubble is in the expanded state and work against each other when the bubble is in the compressed state, thus resulting in a net bubble growth over time.

Crum [12] noted that both effects have to be considered to theoretically model the rectified diffusion process. The kinetics of the bubble growth and collapse is also a crucial factor, expected to control the rectified diffusion. Therefore, a mathematical solution for the growth of a gas bubble by rectified diffusion requires equations of bubble motion, diffusion equations and heat conduction equations for both the liquid and bubble [24]. Consideration of these factors makes it complicated. Both Hsieh and Plesset [36] and Eller and Flynn [37] have taken into account the motion of the bubble wall, and a diffusion equation for the concentration of gas dissolved in the liquid alone. The diffusion of gas in the liquid obeys Fick's law of mass transfer.

Eller and Flynn [37] had shown that rate of change of number of moles $n$ of the gas in the bubble with the time is given as

$$
\frac{d n}{d t}=4 \pi D R_{0} C_{0}\left[\left\langle\frac{R}{R_{0}}\right\rangle+\left(\frac{\left\langle\left(R \mid R_{0}\right)\right\rangle}{\pi D t}\right)^{\frac{1}{2}}\right] H
$$

Where $\mathrm{H}$ is,

$$
H=\frac{C_{i}}{C_{0}}-\left\langle\left(\frac{R}{R_{0}}\right)^{4}\left(\frac{p_{g, m}}{p_{\infty}}\right)\right\rangle\left\langle\left(\frac{R}{R_{0}}\right)^{4}\right\rangle
$$

$C_{i}$ is the concentration of dissolved gas in the liquid far from the bubble and $p_{g, m}$ the instantaneous pressure of the gas in the bubble, $C_{0}$ is the saturation concentration of the gas in the liquid, D is the diffusivity of the gas, and $\left\langle\left(\frac{R}{R_{0}}\right)^{4}\left(\frac{p_{g, m}}{p_{\infty}}\right)\right\rangle,\left\langle\left(\frac{R}{R_{0}}\right)^{4}\right\rangle$ and $\left\langle\frac{R}{R_{0}}\right\rangle$ are the time averages.

Crum later extended Equation 11 to obtain the rate of change of equilibrium bubble radius as a function of time, which is given as

$$
\frac{d R_{0}}{d t}=\frac{D d}{R_{0}}\left[\left\langle\frac{R}{R_{0}}\right\rangle+R_{0}\left(\frac{\left\langle\left(R / R_{0}\right)\right\rangle}{\pi D t}\right)^{1 / 2}\right]\left(1+\frac{4 \sigma}{3 P_{\infty} R_{0}}\right)^{-1}\left(\frac{C_{i}}{C_{0}}-\left\langle\left(\frac{R}{R_{0}}\right)^{4}\left(\frac{p_{g, m}}{p_{\infty}}\right)\right\rangle /\left\langle\left(\frac{R}{R_{0}}\right)^{4}\right\rangle\right)
$$


where, $d=k T C_{0} / P_{\infty}$ ( $\mathrm{K}$ is the universal gas constant, $\mathrm{T}$ is the temperature).

The threshold acoustic pressure growth of a gas bubble is obtained by setting $d R_{0} / d t=0$, and results in the equation

$$
P_{A}^{2}=\frac{\left(\rho R_{0}^{2} \omega_{0}^{2}\right)^{2}\left[\left(1-\omega^{2} / \omega_{0}^{2}\right)^{2}+b^{2}\left(\omega^{2} / \omega_{0}^{2}\right)\right]\left(1+2 \sigma / R_{0} P_{\infty}-C_{i} / C_{0}\right)}{(3+4 K)\left(C_{i} / C_{0}\right)-\left\{\left[\frac{3(\eta-1)(3 \eta-4)}{4}\right]+(4-3 \eta) K\right\}\left(1+2 \sigma / R_{0} P_{\infty}\right)}
$$

Equation 13

Figure 2 represents the rectified diffusion threshold as a function of radius for the radius above and below the resonance values calculated using Equation 13.

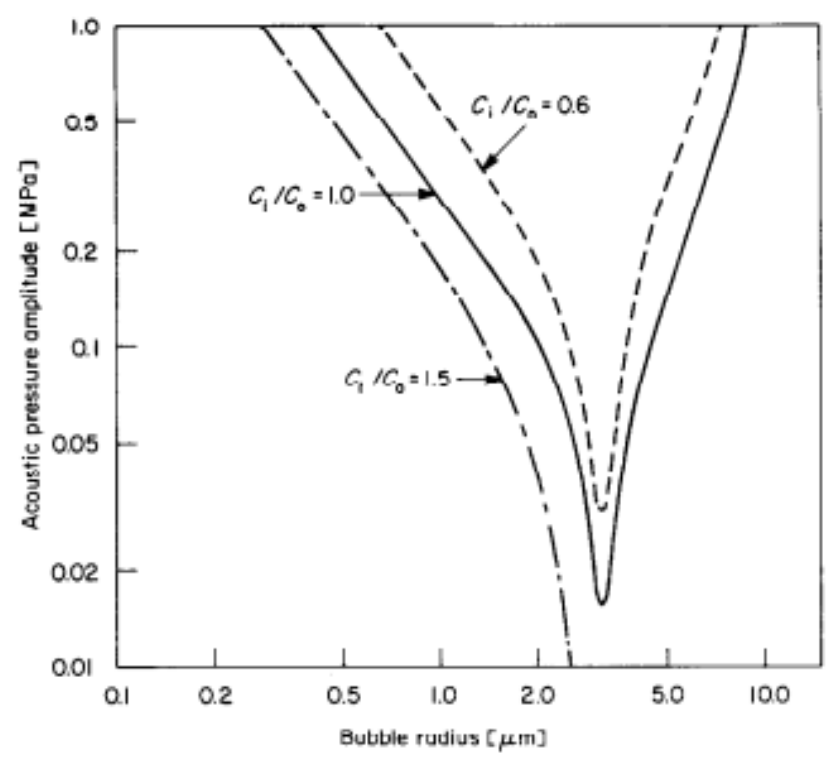

Figure 2: Rectified diffusion threshold as a function of gas bubble radius at different dissolved gas concentration ratios. The curves can be calculated by Equation 13, the acoustic frequency used was 1

$\mathrm{MHz}$ and the surface tension was $68 \mathrm{dyn} / \mathrm{cm}$; the liquid is assumed to be water (Reprinted with permission from Elsevier [24], Copyright (1984)).

Later Fyrillas and Szeri [38] developed a new mathematical analysis for describing the mass transportation during rectified diffusion. They extended the analysis to incorporate the effect of interfacial resistance to mass transfer caused by surfactants. Crum's experimental data was used to estimate the rectified diffusion growth of the cavitation bubbles. Lee et al. [39] and Leong et al. [18] have studied rectified diffusion growth in the presence of various surfactants. They have reported that acoustic streaming, caused due to surfactant adsorption, plays a major role in rectified diffusion growth of bubbles in addition to surface activity and the nature of head group of surfactants [18]. 


\subsubsection{Bubble collapse}

Rectified diffusion leads to the growth of the bubble to a critical (resonance) size, at which the natural bubble oscillation frequency matches that of the driving ultrasound frequency. A simple relationship between the frequency of ultrasound and the resonance radius of a bubble is given by Equation (14) called Minnaert's equation.

$$
F \times R \approx 3
$$

Equation 14

( $\mathrm{F}=$ frequency in $\mathrm{Hz}, \mathrm{R}=$ radius of the bubble in meters $)$

Yasui [26] suggests that resonance size is not a single value but consists of a range. While Equation 14 theoretically predicts the relationship between ultrasound frequency and resonance size of the bubble, experimental data to support this Equation is only recently reported. A pulsed ultrasound technique can be used to determine the resonance size range of sonoluminescence (SL) bubbles and sonochemically (SCL) active bubbles [40-43]. Brotchie et al. [44] have shown for sonochemically active bubbles that with increasing frequency the mean bubble size becomes smaller, and the distribution becomes narrower (Figure 3). SL and SCL have been discussed later in this chapter. Other experimental techniques used to measure the bubble size are laser light diffraction [45], active cavitation detection [46] and phaseDoppler [47].

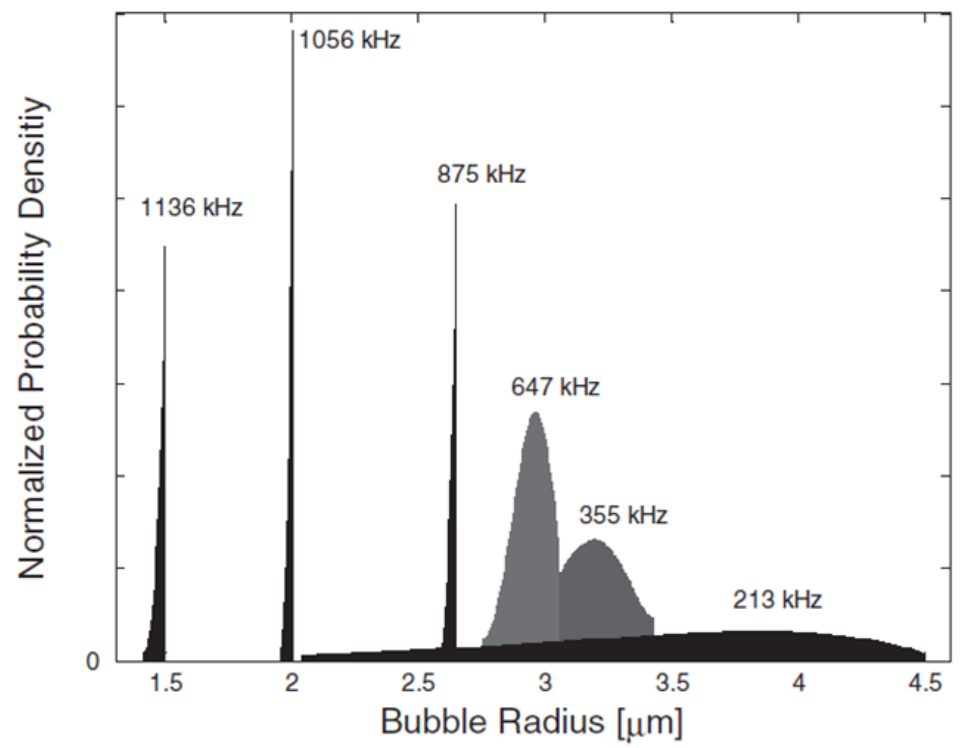

Figure 3: The bubble-size distributions for 213, 355, 647, 875, 1056, and $1136 \mathrm{kHz}$. For 875, 1056, and $1136 \mathrm{kHz}$ data have been scaled down by a factor of 4 . The acoustic power of all frequencies is $1.5 \pm 0.4 \mathrm{~W}$ (Reprinted with permission from American Physical Society [24]; Copyright (2009)).

Once a critical size is reached, the bubble grows to a maximum in a single acoustic cycle and implodes (collapses). The bubble implosion, from a thermodynamic consideration is important because a large change in bubble volume occurs. Since the bubble collapse happens in a very short time domain $(\sim 1 \mu \mathrm{s})$, the "work done" (PdV) leads to a "near" adiabatic heating of the contents of the bubble, which results in the generation of very high temperatures $(>5000 \mathrm{~K}$ ) and pressures (> $1000 \mathrm{~atm})$ within the bubble. 
Rayleigh initially developed the fundamental equation dealing with the collapse of gas cavity in 1917 for an isothermal process, which can be easily extended for an adiabatic process. The model was proposed for a bubble of initial radius of $R_{m}$ and when $\dot{R}=0$, the cavity would collapse, rebound and oscillates between maximum radius $R_{\max }$ and minimum radius $R_{\min } . R$ $=R_{m}$ and $R{ }^{\circ}=0$ in the beginning of the collapse. The pressure of gas inside the bubble is $p_{g, m}$ and temperature is $T_{m}$. Assuming that there is no heat flow across the bubble wall, the gas pressure is given by Equation 15, which follows adiabatic law.

$$
p_{g}=p_{g, m}\left(\frac{R_{m}}{R}\right)^{3 \gamma}
$$

Equation 15

Due to the presence of gases inside the bubble, the decrease in the potential energy will be equal to the sum of kinetic energy of the liquid and amount of work done in compressing the liquid when radius changes from $R_{m}$ to $R$. The energy balance is given as,

$$
-\int_{R_{m}}^{R} p_{\infty} 4 \pi R^{2} d R=2 \pi R^{3} \dot{R}^{2} \rho-\int_{R_{m}}^{R} p_{L} 4 \pi R^{2} d R
$$

Equation 16

The work done can be expressed as

$$
-\int_{R_{m}}^{R} p_{L} d V=\frac{1}{\gamma-1} \frac{4 \pi R_{m}^{3}}{3} p_{g, m}\left\{\left(\frac{R_{m}}{R}\right)^{3 \gamma-1}-1\right\}
$$

Therefore, Equation (16) becomes

$$
\int_{R_{m}}^{R} p_{\infty} 4 \pi R^{2} d R=2 \pi R^{3} \dot{R}^{2} \rho-\frac{1}{\gamma-1} \frac{4 \pi R_{m}^{3}}{3} p_{g, m}\left\{\left(\frac{R_{m}}{R}\right)^{3 \gamma-1}-1\right\}
$$

If in Equation (18), vapour pressure and surface tension are negligible and external pressure i constant, the energy equation described by Noltingk and Neppiras for the collapse becomes,

$$
\frac{3 \rho \dot{R}}{2}=p_{\infty}\left\{\left(\frac{R_{m}}{R}\right)^{3}-1\right\}-p_{g, m} \frac{1}{1-\gamma}\left\{\left(\frac{R_{m}}{R}\right)^{3}-\left(\frac{R_{m}}{R}\right)^{3 \gamma}\right\}
$$

This equation can be solved for calculating $R_{\max }$ and $R_{\min }$ when the velocity $\dot{R}$ of the bubble wall is zero.

$$
p_{\infty}(\gamma-1)\left\{\left(\frac{R_{m}}{R}\right)^{3}-1\right\}=p_{g, m}\left\{\left(\frac{R_{m}}{R}\right)^{3 \gamma}-\left(\frac{R_{m}}{R}\right)^{3}\right\}
$$

Where $R=R_{\max }$ or $R_{\min }$

When $R=R_{\max }$ and if $R=R_{\min } \ll R_{m}$ the Equation 20 reduces to

$$
p_{g, m}\left(\frac{R_{m}}{R_{\min }}\right)^{3(\gamma-1)}=p_{\infty}(\gamma-1)
$$


As $P V^{\gamma}$ and $T V^{(\gamma-1)}$ are constant during the reversible adiabatic compression, the maximum pressure $P_{\max }$ and maximum temperature attained during collapse $T_{\max }$ can be obtained from Equation 21 and is given as

$$
\begin{aligned}
& P_{\text {max }}=p_{g, m}\left(\frac{R_{m}}{R_{\text {min }}}\right)^{3 \gamma} \approx p_{g, m}\left(\frac{p_{\infty}(\gamma-1)}{p_{g, m}}\right)^{\frac{\gamma}{\gamma-1}} \\
& T_{\text {max }}=\left(\frac{R_{m}}{R_{\text {min }}}\right)^{3 \gamma-1} \approx T_{m}\left(\frac{p_{\infty}(\gamma-1)}{p_{g, m}}\right)
\end{aligned}
$$

Equation 23 for calculating the $T_{\max }$ tends to overestimate the collapse temperature because it does not take into account the heat leaking from the bubble into the surrounding fluid or the thermal conductivity of the gases or the energy consumed in the decomposition of the vapour/gas within the bubble. Figures $4 \& 5$ show the results of the numerical simulation of the pulsation of an isolated spherical air bubble in water irradiated with $300 \mathrm{kHz}$ and 3-bar, calculated by Yasui et al.[48] using the bubble dynamics equations. The temperature at the end of the bubble collapse (Rayleigh collapse) increased up to $5100 \mathrm{~K}$ (Figure 5a) whereas pressure reaches to $6 \times 10^{9} \mathrm{~Pa}$ (Figure $5 \mathrm{~b}$ ).

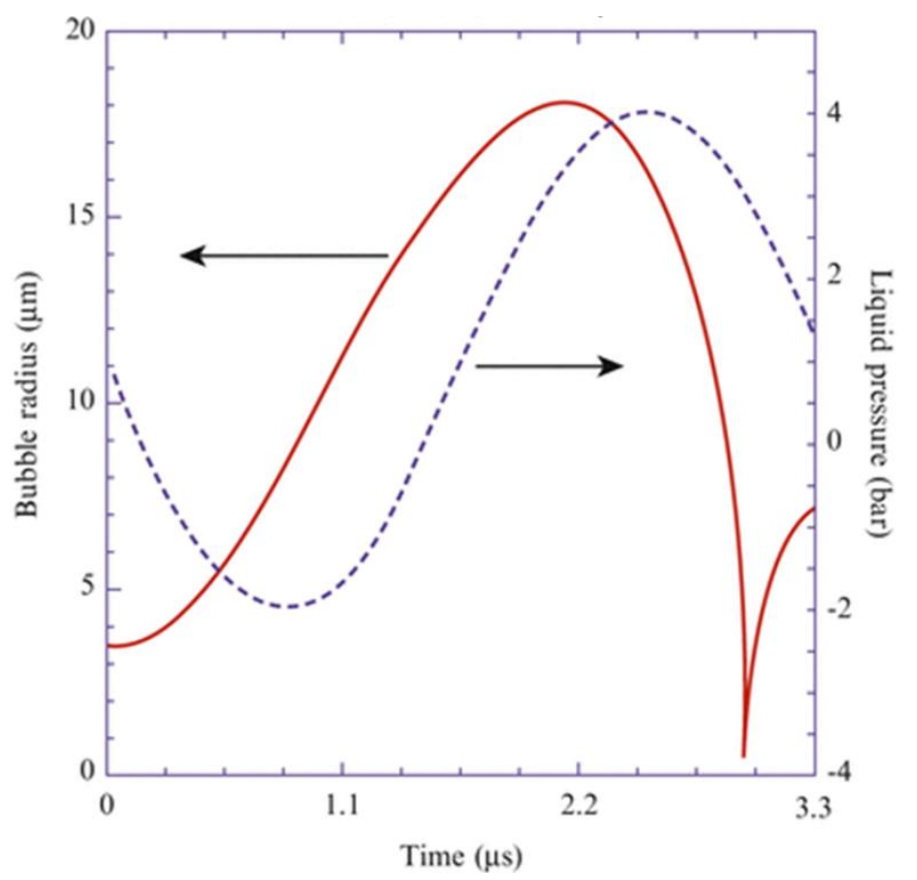

Figure 4: The result of the numerical simulation of the bubble radius as a function of time for one acoustic cycle $(3.3 \mu \mathrm{s})$ when the frequency and pressure amplitude of an ultrasonic wave are $300 \mathrm{kHz}$ and 3 bars, respectively. The ambient radius of an isolated spherical air bubble is $3.5 \mu \mathrm{m}$. The dotted line is the acoustic pressure (plus the ambient pressure) as a function of time (Reprinted with permission from AIP Publishing LLC [48]; Copyright (2007)). 

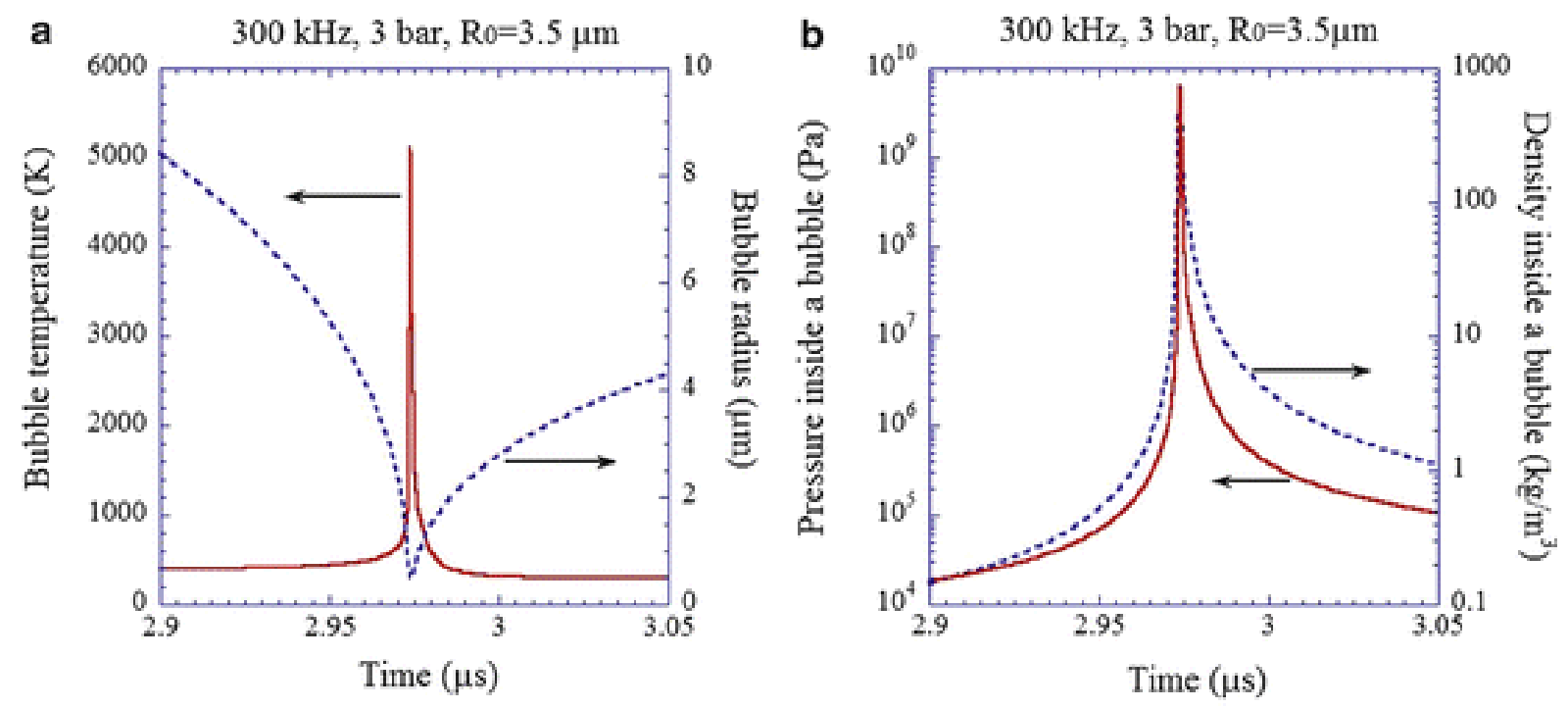

Figure 5: The results of the numerical simulation. (a) The bubble radius (dotted line) and the temperature inside a bubble (solid line). (b) The pressure (solid line) and the density (dotted line) inside a bubble with logarithmic vertical axes.(Reprinted with permission from AIP Publishing LLC [48]; Copyright (2007)).

Similar are the results shown by Merouani et al. (Figure 6) [49]. The temperature and pressure calculated inside a bubble increase suddenly at the end of the bubble collapse up to $4600 \mathrm{~K}$ and $1400 \mathrm{~atm}(\sim 140 \mathrm{MPa})$, respectively.

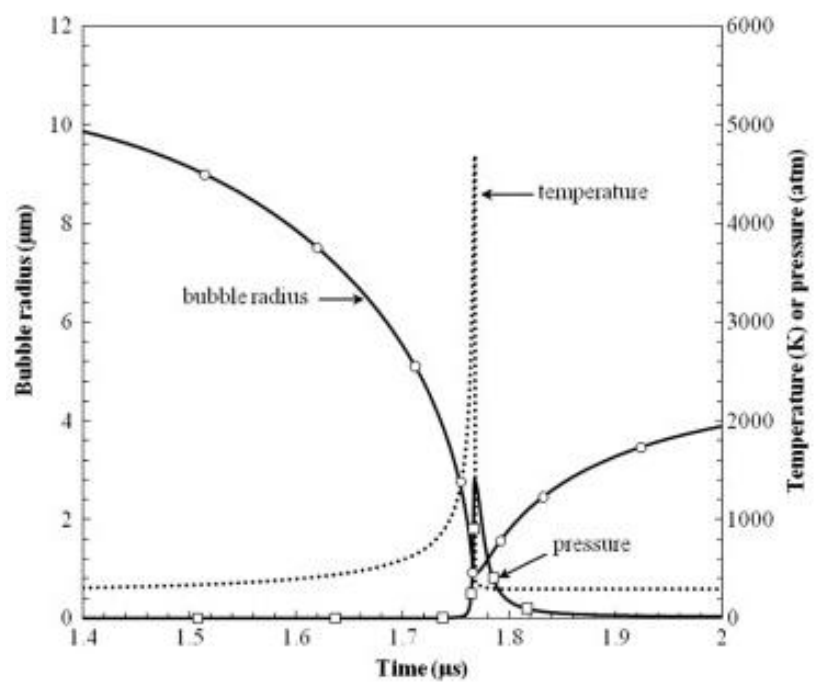

Figure 6: Bubble radius and temperature and pressure inside a bubble as function of time during the collapse phase of the bubble. The horizontal axis is only for $0.6 \mu \mathrm{s}$. A maximum bubble temperature and pressure of about $4600 \mathrm{~K}$ and $1400 \mathrm{~atm}(\sim 140 \mathrm{MPa})$, respectively are achieved at the end of the collapse. (Reprinted with permission from Elsevier [49]; Copyright (2014)).

A number of techniques have been developed for the experimental determination of the $T_{\max }$. Misík et al. [50], using kinetic isotope effect of the sonolysis of $\mathrm{H}_{2} \mathrm{O} / \mathrm{D}_{2} \mathrm{O}$ mixtures, found 
that the cavitation temperatures determined were dependent on the specific spin trap used and are in the range of 1000-4600 K. Mean temperatures in different regions of a "hot spot" were postulated by Suslick et al. [51], using comparative rate thermometry in alkane solutions. They have proposed a gas phase zone within the collapsing cavity with an estimated temperature and pressure of $5200 \pm 650 \mathrm{~K}$ and $500 \mathrm{~atm}$, respectively, and a thin liquid layer immediately surrounding the collapsing cavity with an estimated temperature of $1900 \mathrm{~K}[51]$.

Henglein studied the sonolysis of methane to estimate the bubble core temperature [52]. The method is termed as methyl radical recombination (MRR) method. Sonication of methane leads to the reaction in the liquid medium:

$$
\begin{aligned}
& \mathrm{CH}_{4} \rightarrow \mathrm{CH}_{3}+\mathrm{H}^{\cdot} \\
& \mathrm{H}_{2} \mathrm{O} \rightarrow \mathrm{H}^{\cdot}+\mathrm{OH}^{\cdot} \\
& \mathrm{H}^{\cdot}+\mathrm{CH}_{4} \rightarrow \mathrm{CH}_{3}+\mathrm{H}_{2} \\
& \mathrm{OH}^{\cdot}+\mathrm{CH}_{4} \rightarrow \mathrm{CH}_{3}+\mathrm{H}_{2} \mathrm{O} \\
& \mathrm{CH}_{3}+\mathrm{CH}_{3} \rightarrow \mathrm{C}_{2} \mathrm{H}_{6} \\
& \mathrm{CH}_{3}+\mathrm{CH}_{3} \rightarrow \mathrm{C}_{2} \mathrm{H}_{4}+\mathrm{H}_{2}
\end{aligned}
$$

Reaction 1

Reaction 2

Reaction 3

Reaction 4

Reaction 5

Reaction 6

The temperature dependence of the rate constants involved during the formation of ethane and ethylene (Reactions $5 \& 6$ ) is shown in Figure 7. The rate constant for the formation of ethylene increases with an increase in temperature whereas that for the formation of ethane has negligible dependence on the temperature. Figure 7 also shows the dependence of ratio of $\mathrm{k}_{\text {ethylene }} / \mathrm{k}_{\text {ethane }}\left(=\right.$ yield $\left._{\text {ethylene}} / \mathrm{yield}_{\text {ethane }}\right)$ as a function of temperature which can used to estimate the bubble temperature. Temperatures in the range of $1930 \mathrm{~K}$ to $2720 \mathrm{~K}$ have been estimated using this method.
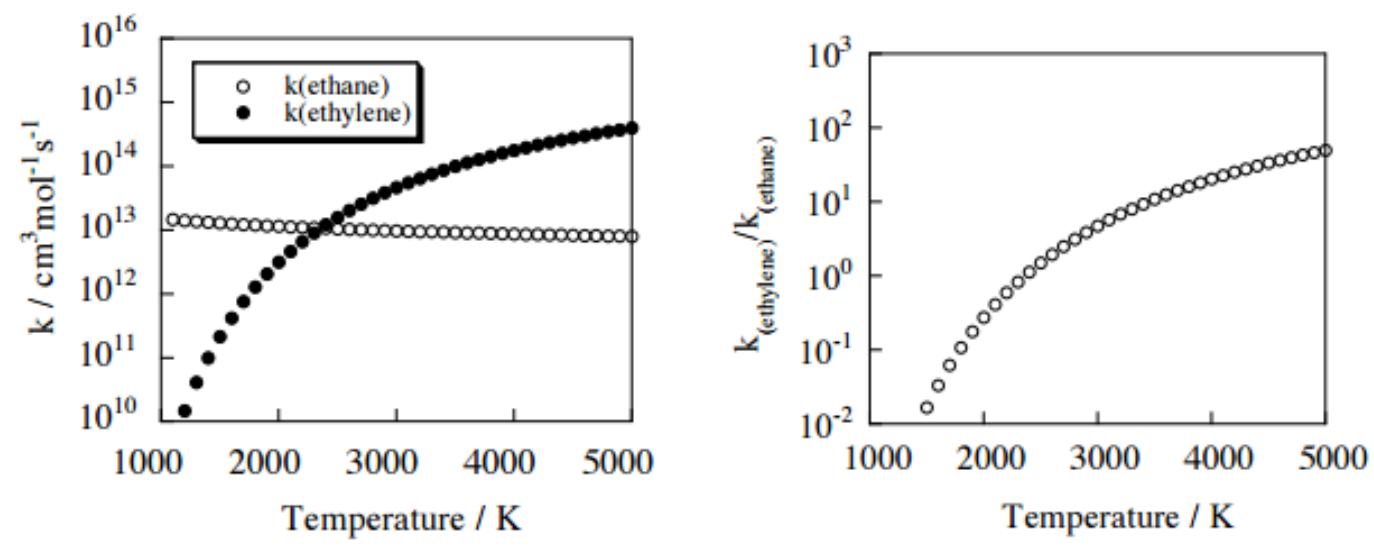

Figure 7: The rate constants for the formation of ethane and ethylene as a function of temperature (left) and temperature dependence of the ratio, $\mathrm{k}_{\text {ethylene }} / \mathrm{k}_{\text {ethane }}(r i g h t)$ (Reprinted with permission from Elsevier [52]; Copyright (1990)). 
Tauber et al. estimated the temperature in the range of $2300 \mathrm{~K}$ and $3600 \mathrm{~K}$ using the MRR method by studying the sonolysis of n-butanol [53]. Grieser and coworkers [54, 55] noted that cavitation bubble temperature is affected by the surface activity of alcohols used to generate methyl radicals.

\subsection{Physical \& chemical effects generated by acoustic cavitation}

The sudden violent collapse of a cavitation bubble gives rise to a number of physical and chemical effects in the liquid such as microstreaming, agitation, turbulence, microjetting, shock waves, generation of radicals, sonoluminescence etc. [19]. Shock waves are produced when the bubble collapse symmetrically [19]. However, when the bubble collapse unsymmetrically (mostly at a boundary), it leads to the formation of a jet in the liquid (Figure 8) [56] due to the uneven acoustic field around the bubble.

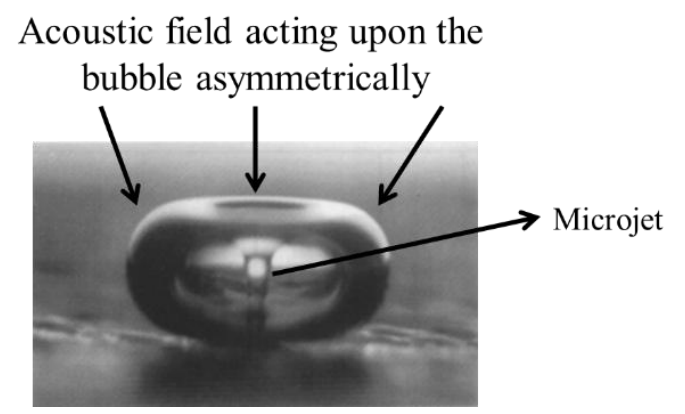

Figure 8: Microjet formation when a bubble collapses near solid surface; Adapted from [57].

The microjets have velocities of the order of $100 \mathrm{~m} / \mathrm{s}$. The effect of shock waves and microstreaming together with the transition from high to low flow velocities away from the bubble surface generates extensive amount shear stresses [57]. The generation of very high temperatures on bubble collapse leads to local heating. The heat generated can raise the temperature of the core of the bubbles to thousands of degrees for a short period (micro- to nanoseconds). Such extreme thermal conditions lead to light emission from the bubbles, referred to as sonoluminescence [58]. It was first observed in 1933 by Marinesco and Trillant [59]. Frenzel and Schultes [7] and Griffing and Sette [60] were the first to detect sonoluminescence using photomultipliers with accurate temporal resolution. Sonoluminescence can be divided in to two categories [61]. A large number of cavitation bubbles generates multibubble sonoluminescence (MBSL). Single bubble sonoluminescence (SBSL) refers to emission observed from a stably oscillating single bubble in a liquid. The change in radius of a single bubble within one acoustic cycle is shown in Figure 9 [1, 61-63]. The relative scattered intensity is proportional to radius of the bubble. Using a stroboscopic technique, images of an oscillating bubble were recorded and shown in Figure 9. SL emission could also be observed at the end of bubble collapse. 


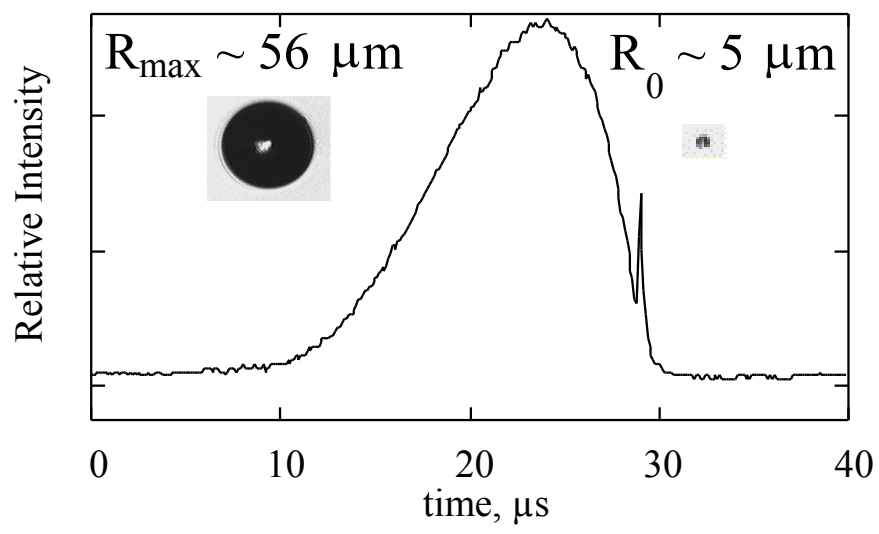

Figure 9: Relative scattered light intensity, proportional to the size of the bubble, as a function of time. Bubble growth is a relatively slow process compared to the collapse. The spike observed near end of collapse phase is the SL emission, Adapted from [1].

The intensity of SL depends on the nature of liquid medium [64, 65], amount of dissolved gases [66, 67], hydrostatic pressure [68], acoustic pressure amplitude [9, 60], and acoustic frequency [60, 69]. Different theoretical models have been proposed for SL. One model is based on inward moving shock waves during bubble collapse: it is believed that light is emitted from the bubble centre where plasma is created by the shock-wave convergences [7072]. Another is quasiadiabatic compression model, where a bubble is heated by the quasiadiabatic compression [73, 74]. Both SBSL and MBSL originates from quasiadiabatic compression $[62,75]$. However, Yasui has proposed that sonoluminescence is originated by the heat generated from whole of the bubble rather than a local point $[62,74]$ and has constructed a theoretical model for SL. Yasui has suggested that SL is due to both electronion radiative recombination and electron atom Bremsstrahlung [75]. The mechanism behind the SL observed from the noble gas bubbles is usually radiative recombination of electrons and ions and electron-atom bremsstrahlung [62].

The intensity of light emission from cavitation bubbles can be increased significantly by adding a small amount of luminol in aqueous alkaline solutions. This emission is referred to as sonochemiluminescence (SCL) [76-79], which arise due to the reaction between $\mathrm{OH}$ radicals and luminol. Thus, SCL indicates chemically active region in a reactor. Ashokkumar et al. $[78,79]$ have shown that two groups of cavitation bubbles exist. One group of bubbles reach higher temperatures for SL to occur and the $2^{\text {nd }}$ group causing chemical reactions (Figure 10). It can be seen in the figure that SL occurs only in a small region closer to the liquid/water interface. It was speculated that these bubbles experience relatively larger acoustic force due to the reflected waves at the air/liquid interface. It can also be observed that chemical activity could be observed throughout the reactor from cavitation bubbles that reach a relatively lower temperature enough to cause chemical reactions $(\mathrm{OH}$ radical generation). 


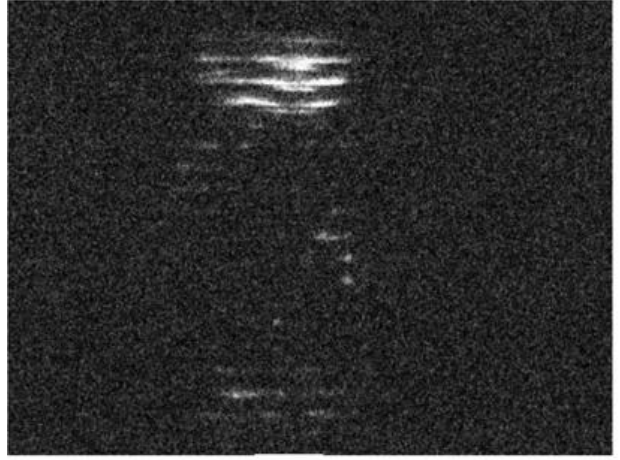

(a)

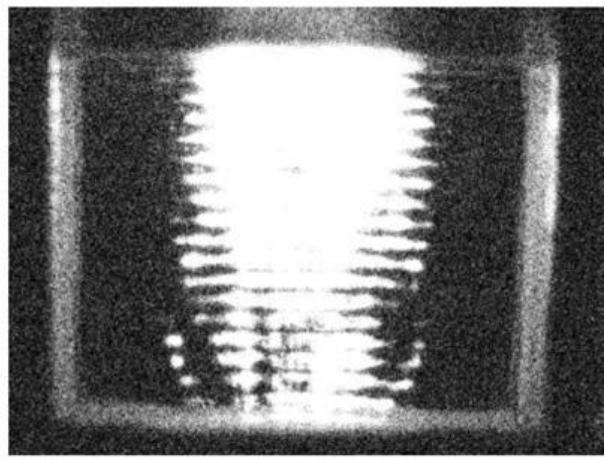

(b)

Figure 10: Sonoluminescence from water and (b) sonochemiluminescence from an aqueous solution containing luminol; frequency $=170 \mathrm{kHz}$; power $=12 \mathrm{~W}$ (Reprinted with permission from John Wiley and Sons [78]; Copyright (2010)).

The speculation that SL bubbles reach relatively higher temperatures is supported by the experimental data published later. A comparison between the size distributions of SL emitting and sonochemistry producing cavitation bubbles was studied by Brotchie et al. [44]. They have shown that SL emitting bubbles are larger than sonochemically active bubbles (Figure 11) [44].

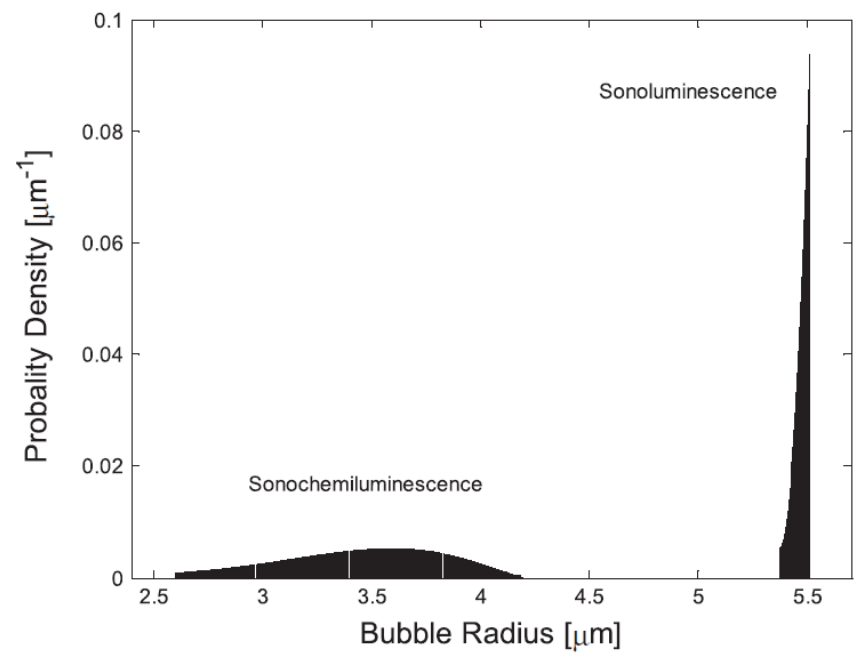

Figure 11: Bubble radius distribution of SL and SC bubbles. Frequency: $575 \mathrm{kHz}$ (Reprinted with permission from American Physical Society [44]; Copyright (2009))

Another consequence of the extreme conditions of ultrasound is that it leads to a variety of chemical reactions (formation of highly reaction radical species). When the argon saturated liquid is sonicated formation of $\mathrm{H}^{-}$and $\mathrm{OH}^{-}$radicals (Reaction 2) takes place as majority of bubble content is water vapours. $\mathrm{H}$ radicals are reducing in nature whereas $\mathrm{OH}$. radicals are oxidising in nature.

$\mathrm{CH}_{4} \rightarrow \mathrm{CH}_{3}+\mathrm{H}^{\cdot}$

Reaction 1 


$$
\begin{array}{lr}
\mathrm{H}_{2} \mathrm{O} \rightarrow \mathrm{H}+\mathrm{OH}^{\cdot} & \text { Reaction 2 } \\
\mathrm{H}^{\cdot}+\mathrm{CH}_{4} \rightarrow \mathrm{CH}_{3}+\mathrm{H}_{2} & \text { Reaction 3 } \\
\mathrm{OH}^{\cdot}+\mathrm{CH}_{4} \rightarrow \mathrm{CH}_{3}+\mathrm{H}_{2} \mathrm{O} & \text { Reaction 4 } \\
\mathrm{CH}_{3}+\mathrm{CH}_{3} \rightarrow \mathrm{C}_{2} \mathrm{H}_{6} & \text { Reaction 5 } \\
\mathrm{CH}_{3}+\mathrm{CH}_{3} \rightarrow \mathrm{C}_{2} \mathrm{H}_{4}+\mathrm{H}_{2} & \text { Reaction 6 }
\end{array}
$$

A number of techniques have been used to confirm the formation and quantification of radical species. ESR spin traps and chemical dosimeters have been used for the quantification of the radical produced during sonication $[50,80,81]$. Another method is the reaction between teraphthalic acid and $\mathrm{OH}^{\cdot}$ radicals which leads to the formation of fluorescent hydroxyterephthalic acid [81, 82]. The intensity of fluorescence can be utilized to quantify the amount of $\mathrm{OH}$ ' radicals generated during cavitation. A simple method called 'Weissler' method can be used to quantify $\mathrm{OH}$ Radicals, which is based on the oxidation of iodide ions $[1,83]$. In this method, $\mathrm{OH}$ radicals react to produce hydrogen peroxide (Reaction 7 ) which can oxidize iodide ions to molecular iodine (Reaction 8 ). When excess of iodide ions are present, molecular iodine is converted into the triiodide complex (Reaction 9). Triiodide has absorption maximum at $353 \mathrm{~nm}$ which can be used to quantify the amount of iodine, and hence the amount of $\mathrm{OH}^{\prime}$ radicals generated.

$2 \mathrm{OH} \rightarrow \mathrm{H}_{2} \mathrm{O}_{2}$

Reaction 7

$\mathrm{H}_{2} \mathrm{O}_{2}+2 \mathrm{I}^{-} \rightarrow 2 \mathrm{OH}^{-}+\mathrm{I}_{2}$

Reaction 8

$I_{2}+I^{-} \rightarrow I_{3}^{-}$

Reaction 9

\subsection{Single bubble sonochemistry}

In air-saturated water, a variety of radicals and molecular products such as $\mathrm{H}_{2} \mathrm{O}_{2}, \mathrm{HO}_{2}, \mathrm{O}, \mathrm{O}_{3}$, $\mathrm{HNO}_{2}, \mathrm{HNO}_{3}, \mathrm{H}_{2}$, and $\mathrm{OH}$ radicals (Reactions 2, 7, 10-15) are generated (Figure 12c).

$\mathrm{O}_{2} \rightarrow 20$

Reaction 10

$\boldsymbol{O}+\mathrm{O}_{2} \rightarrow \mathrm{O}_{3}$

Reaction 11

$\mathrm{H}+\mathrm{O}_{2} \rightarrow \mathrm{HO}_{2}$

Reaction 12

$2 \mathrm{HO}_{2} \rightarrow \mathrm{H}_{2} \mathrm{O}_{2}+\mathrm{O}_{2}$

Reaction 13

$\mathrm{N}_{2}+\mathrm{O}_{2} \rightarrow 2 \mathrm{NO}$

Reaction 14

$2 \mathrm{NO}+\mathrm{O}_{2} \rightarrow 2 \mathrm{NO}_{2}$

Reaction 15

The quantification of primary radicals and molecular products in multibubble systems has been extensively studied [26, 44, 55, 84-88]. Such information for a single bubble system has 
also been theoretically studied [48, 49, 89]. Only in the past decade, experimental details on the amount of radicals and molecular products generated for single bubble systems became available $[62,76,90]$.

Yasui et al. [89] have numerically calculated chemical reaction yield for a single cavitation bubble. In Figure 12a, the changes in bubble radius and temperature inside a bubble are shown. It is seen that the temperature inside a bubble increases at the end of bubble collapse up to $6500 \mathrm{~K}$, which is much lower than that measured in argon saturated bubble because the molar specific heat of nitrogen and oxygen is larger than that of argon. Figure $12 \mathrm{~b}$ shows the number of different molecules produced inside a bubble. The bubble content mostly consists of nitrogen, oxygen, and water vapour and main chemical products obtained in this case are $\mathrm{HNO}_{3}, \mathrm{HNO}_{2}, \mathrm{O}$, and $\mathrm{H}_{2} \mathrm{O}_{2}$. Figure $12 \mathrm{c}$ shows the intensity of the light emitted from a bubble. SL is only emitted at the end of the bubble collapse having pulse width of about 60 ps. The number of photons emitted is equal to $1.53 \times 10^{4}$, which was found to be $20 \%$ less than that of in the case of argon saturated bubble as the SL intensity is affected by the amount and nature of the dissolved gases. Yasui observed that the these results were consistent with the experimental observation by Matula and Crum [91].
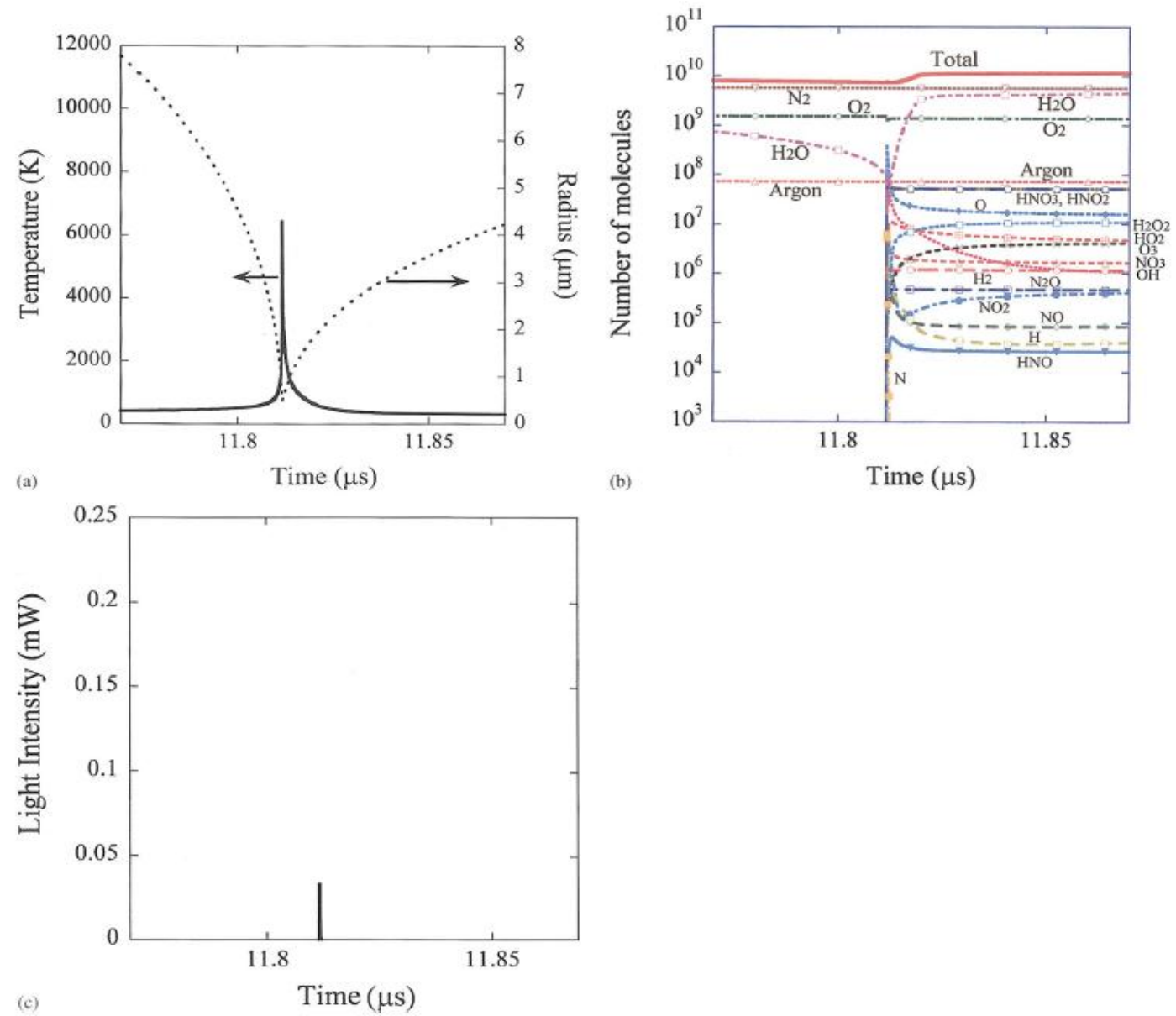

Figure 12: The calculated results for an initial air bubble at around the end of the bubble collapse only for $0.1 \mathrm{~ms}$. (a) The bubble radius and the temperature inside a bubble. (b) The number of molecules inside a bubble. (c) The intensity of the light emitted from a bubble (Reprinted with permission from AIP Publishing LLC [89]; Copyright (2005)). 
Didenko and Suslick have determined the amount of different chemical products experimentally. Table 1 shows the average amounts of chemical products per acoustic cycle. It can be seen from the date shown in Table 1 that the main chemical products are hydrogen molecule, oxygen atom, hydrogen peroxide, hydrogen atom, and nitrous acid. According to Didenko and Suslick [90], the amount of $\mathrm{OH}$ radicals that diffuses into the liquid after one acoustic cycle is $8.2 \times 10^{5}$ (number of molecules,) which is consistent with the calculated result of $6.6 \times 10^{5}$. The generation of $\mathrm{NO}_{2}$ and further reaction of $\mathrm{NO}_{2}$ with $\mathrm{H}_{2} \mathrm{O}$ leads to the formation of nitric acid [92]. It is for this reason that sonication of air-saturated water leads to a decrease in solution $\mathrm{pH}$ [1]. The amount of $\mathrm{NO}_{2}{ }^{-}$ions produced in one acoustic cycle was experimentally determined by Didenko and Suslick [90] was $9.9 \times 10^{6}$ (number of molecules) (Table 1). A similar number was reported by Koda et al. [93], which was found to be larger than the numerically calculated value by Yasui et al. [89].

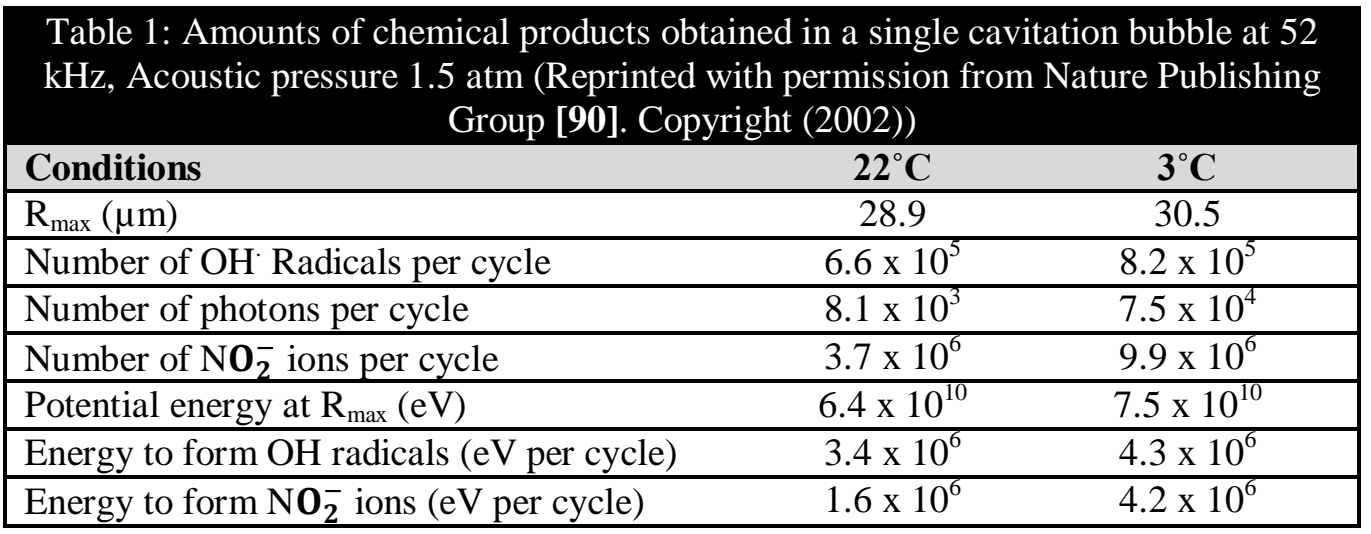

In Table 2, the average amount of chemical products diffusing into a liquid per acoustic cycle for the case of an air bubble is shown. A single bubble trapped at the pressure antinode of a standing ultrasonic wave initially consists mainly of air, and its main content gradually changes to argon. Yasui et al. [89] have shown that the average amount of $\mathrm{HNO}_{2}\left(4.0 \times 10^{7}\right)$ dissolving in the liquid per oscillation from an initial air bubble is an order of magnitude larger than that from a SBSL bubble in steady state (an argon bubble) and it is even larger than the experimentally reported value of $9.9 \times 10^{6}$. This suggests that the experimentally reported production rate of $\mathrm{NO}_{2}{ }^{-}$ions maybe the time averaged value during the course of the gradual change of the bubble content from air to argon. The amount of $\mathrm{OH}$ radicals $9.9 \times 10^{5}$ dissolving into liquid from an initial air bubble is not so different from that $6.6 \times 10^{5}$ from a SBSL bubble in a steady state and is consistent with the experimentally reported value $8.2 \mathrm{x}$ $10^{5}$.

The main oxidants dissolved in the liquid are oxygen and hydrogen peroxide besides the $\mathrm{OH}$ radicals. It has been found that in a multibubble system, where a standing wave is established, many bubbles behave as single spherical SBSL bubbles [87, 89, 94-97]. The reason behind this is Bjerkness force. The radiation force, which acts on the bubbles leads to the gathering of bubbles at the regions where the acoustic amplitude is comparable cavitation threshold. It has been concluded that even in a multibubble system oxidant produced is not only $\mathrm{OH}$ radicals but also oxygen atom and hydrogen peroxide irrespective of the effect of neighbouring bubbles on the bubble dynamics, shielding of acoustic field, etc. [89, 98]. According to Yasui et al. [89], $\mathrm{O}$ atom may have been created by the dissociation of oxygen molecules and water vapour molecules inside the collapsing bubble as given in Reactions 1619 (radicals are represented in bold letters; $M$ is an inert third body). 
$O_{2}+M \rightarrow \boldsymbol{O}+\boldsymbol{O}+M$

Reaction 16

$\boldsymbol{O H}+M \rightarrow \boldsymbol{O}+\boldsymbol{H}+M$

Reaction 17

$\mathrm{N}_{2}+\mathrm{O}_{2} \rightarrow \boldsymbol{O}+\mathrm{N}_{2} \mathrm{O}$

Reaction 18

$\mathrm{O}_{2}+\mathrm{N} \rightarrow \boldsymbol{O}+\mathrm{NO}$

Reaction 19

Table 2: the average amount of chemical products that dissolve into the liquid from the interior of an initial air bubble in one acoustic cycle (Reprinted with permission from AIP Publishing LLC [89]; Copyright (2005))

Chemical species Number of molecules per acoustic cycle

\begin{tabular}{|cl|}
\hline $\mathrm{HNO}_{2}$ & $4.0 \times 10^{7}$ \\
\hline $\mathrm{HNO}_{3}$ & $3.7 \times 10^{7}$ \\
\hline $\mathrm{O}$ & $1.6 \times 10^{7}$ \\
\hline $\mathrm{H}_{2} \mathrm{O}_{2}$ & $5.1 \times 10^{6}$ \\
\hline $\mathrm{O}_{3}$ & $2.7 \times 10^{6}$ \\
\hline $\mathrm{HO}_{2}$ & $2.3 \times 10^{6}$ \\
\hline $\mathrm{NO}_{3}$ & $1.1 \times 10^{6}$ \\
\hline $\mathrm{H}_{2}$ & $1.0 \times 10^{6}$ \\
\hline $\mathrm{OH}_{2}$ & $9.9 \times 10^{5}$ \\
\hline $\mathrm{NO}_{2} \mathrm{O}$ & $3.9 \times 10^{5}$ \\
\hline $\mathrm{NO}$ & $3.0 \times 10^{5}$ \\
\hline $\mathrm{H}$ & $1.3 \times 10^{5}$ \\
\hline $\mathrm{HNO}$ & $1.1 \times 10^{5}$ \\
\hline $\mathrm{N}$ & $2.8 \times 10^{4}$ \\
\hline $\mathrm{N}_{2} \mathrm{O}_{5}$ & $2.7 \times 10^{3}$ \\
\hline & $6.8 \times 10^{2}$ \\
\hline
\end{tabular}

Different methods to estimate the amount of oxygen atoms have been reported in the literature [99-101]. In 1985, Hart and Henglein [102] suggested that $O$ atoms created inside a bubble may oxidize $\mathrm{I}^{-}$ion in an aqueous KI solution containing a mixture of argon and $\mathrm{O}_{2}$. In their experimental results (Figure 13), the amount of $\mathrm{I}_{2}$ production in aqueous KI solution was considerably larger than that of $\mathrm{H}_{2} \mathrm{O}_{2}$ generated in pure water (in the absence of $\mathrm{O}_{2}$ ). Based on this observation, they concluded that there should be some oxidant such as $\mathrm{O}$ in addition to $\mathrm{OH}$ radicals and $\mathrm{H}_{2} \mathrm{O}_{2}$. Hart and Henglein [102] as well as Yasui [89] suggested that considerable amount of $\mathrm{O}$ atoms can be produced in an air filled collapsing bubble. Therefore sonochemistry can serve as important tool to study the chemical reactions of oxygen atom in liquids [103]. 


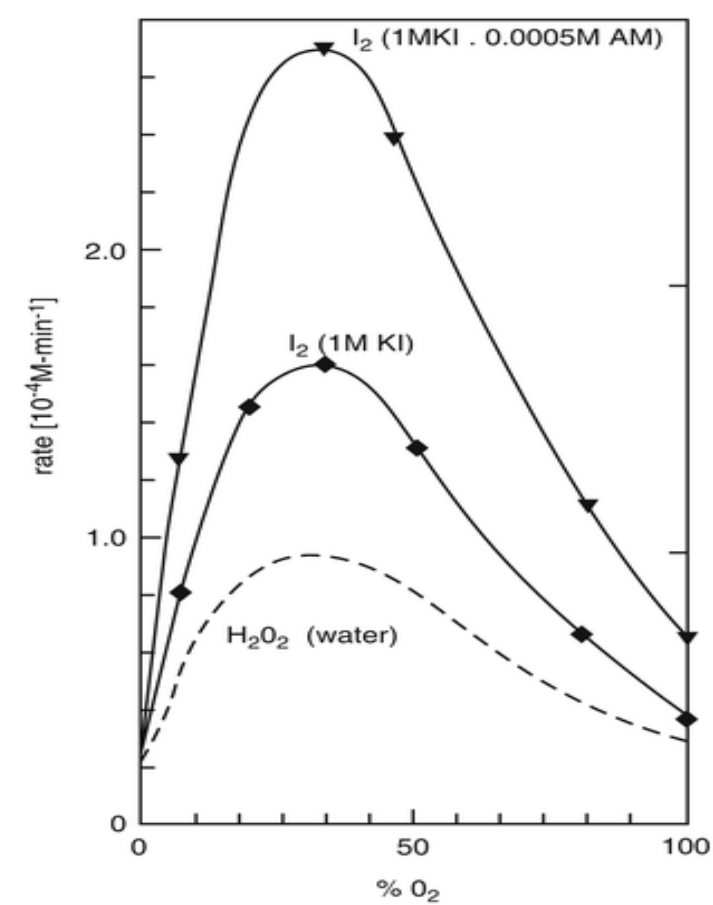

Figure 13: Experimental results of the rate of production of $\mathrm{H}_{2} \mathrm{O}_{2}$ in pure water and $\mathrm{I}_{2}$ in $1 \mathrm{M} \mathrm{KI}$ solution or $1 \mathrm{M} \mathrm{KI}+0.0005 \mathrm{M}$ ammonium molybdate solution under different mixtures of argon and oxygen dissolved in the solution (Reprinted with permission from American Chemical Society [102];

Copyright (1985)).

\subsection{Effect of ultrasound frequency on sonochemistry}

The extent of sonochemical reactions (for example, yield of primary and secondary radicals) and sonoluminescence intensity produced by acoustic cavitation depends on the frequency, power, etc. Various methods have been used to estimate the cavitation yield such as the amount chemical products obtained, $\mathrm{T}_{\max }$, SL intensity etc. as a function of acoustic frequency. Yasui et al. [48] have estimated the average temperature and rate of production of main oxidant $\mathrm{OH}$ at different frequencies $(20,100,300$ and $1 \mathrm{MHz})$ as a function acoustic amplitude (Figure 14). At lower frequencies $(20 \mathrm{kHz}$ and $100 \mathrm{kHz})$, maximum temperature was reached at relatively lower acoustic amplitudes. This is due to bubble expansion to a relatively larger volume caused by the longer acoustic period, resulting in an increase in the amount of water vapour inside a bubble [104]. For a vaporous bubble, which is defined as a bubble with higher molar fraction of vapour than 0.5 at the end of the bubble collapse, the main oxidant created is $\mathrm{OH}$ radicals [48].

The amount of $\mathrm{H}_{2} \mathrm{O}_{2}$ produced at $100 \mathrm{kHz}$ is higher compared to that produced at $20 \mathrm{kHz}$ because a high temperature is maintained at $20 \mathrm{kHz}$ for longer time as compared to higher frequencies, which can dissociate $\mathrm{H}_{2} \mathrm{O}_{2}$ into $\mathrm{OH}$ radicals. It has been shown that $\mathrm{T}_{\max }$ is proportional to $\mathrm{R}_{\max }$ for the frequencies greater than $16 \mathrm{kHz}$ [105]. It has been observed for a gaseous bubble that when the molar fraction of vapour is less than 0.5 , the collapse temperature ranges from $4000 \mathrm{~K}$ to $6500 \mathrm{~K}$ and the main oxidant is $\mathrm{H}_{2} \mathrm{O}_{2}$. However, when the bubble temperature is greater than $6500 \mathrm{~K}$ in gaseous bubbles, the main oxidant is $\mathrm{O}$ atom. The consumption of oxidants took place inside an air bubble by an oxidizing nitrogen when the bubble temperature is higher than $7000 \mathrm{~K}$ and the main chemical products are $\mathrm{HNO}_{2}, \mathrm{NO}$, and $\mathrm{HNO}_{3}[48,106]$. 

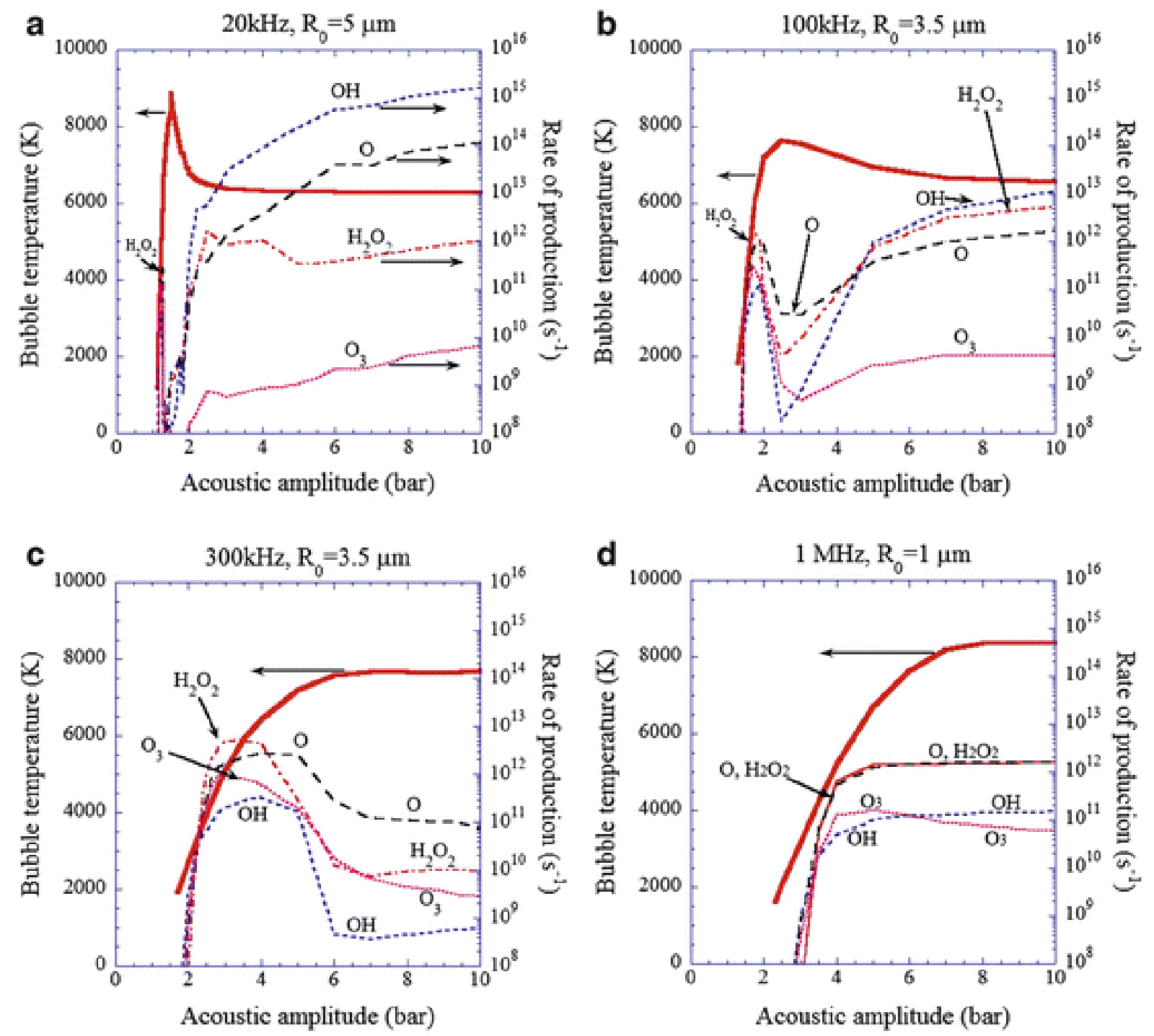

Figure 14: The numerical simulations on the rate of production of each oxidant inside an isolated air bubble per second estimated by the first bubble collapse as a function of acoustic amplitude with the temperature inside a bubble at the end of the bubble collapse ( the thick line): (a) $20 \mathrm{kHz}$ and $\mathrm{R}_{0}=5$ $\mu \mathrm{m}$. (b) $100 \mathrm{kHz}$ and $\mathrm{R}_{0}=3.5 \mu \mathrm{m}$. (c) $300 \mathrm{kHz}$ and $\mathrm{R}_{0}=3.5 \mu \mathrm{m}$. (d) $1 \mathrm{MHz}$ and $\mathrm{R}_{0}=1 \mu \mathrm{m}$ (Reprinted with permission from AIP Publishing LLC [48]; Copyright (2007)).

While Yasui's calculations on frequency effect are based on a single bubble system, the overall chemical activity in a multibubble system should be looked at with a different approach. While single bubble dynamics calculations provide an avenue to theoretically calculate bubble temperatures, chemical yield, sonoluminescence intensity, etc., such calculations may not provide insight into multibubble systems. Single bubble calculations tend to provide overestimates of bubble temperatures and chemical yields in when multibubble systems are considered. This is due to various factors that include bubble clustering, bubble coalescence, asymmetric collapse of bubbles, inhomogeneous nature of acoustic field, etc.

It is well known that with an increase in frequency, the number of antinodes and hence the number of cavitation bubbles generated increase. Figure 15 shows the schematic and 
photographic images of the standing waves observed at 37 and $440 \mathrm{kHz}$, which clearly illustrates the increase in the number of standing waves as well as the bubble population. It has been noted that the radical yield increases with an increase in frequency, reaches a maximum value and decreases with further increase in the frequency. The highest sonochemical yield is obtained between $200-800 \mathrm{kHz}$ and demonstrated in various studies [61, 86, 107-109].
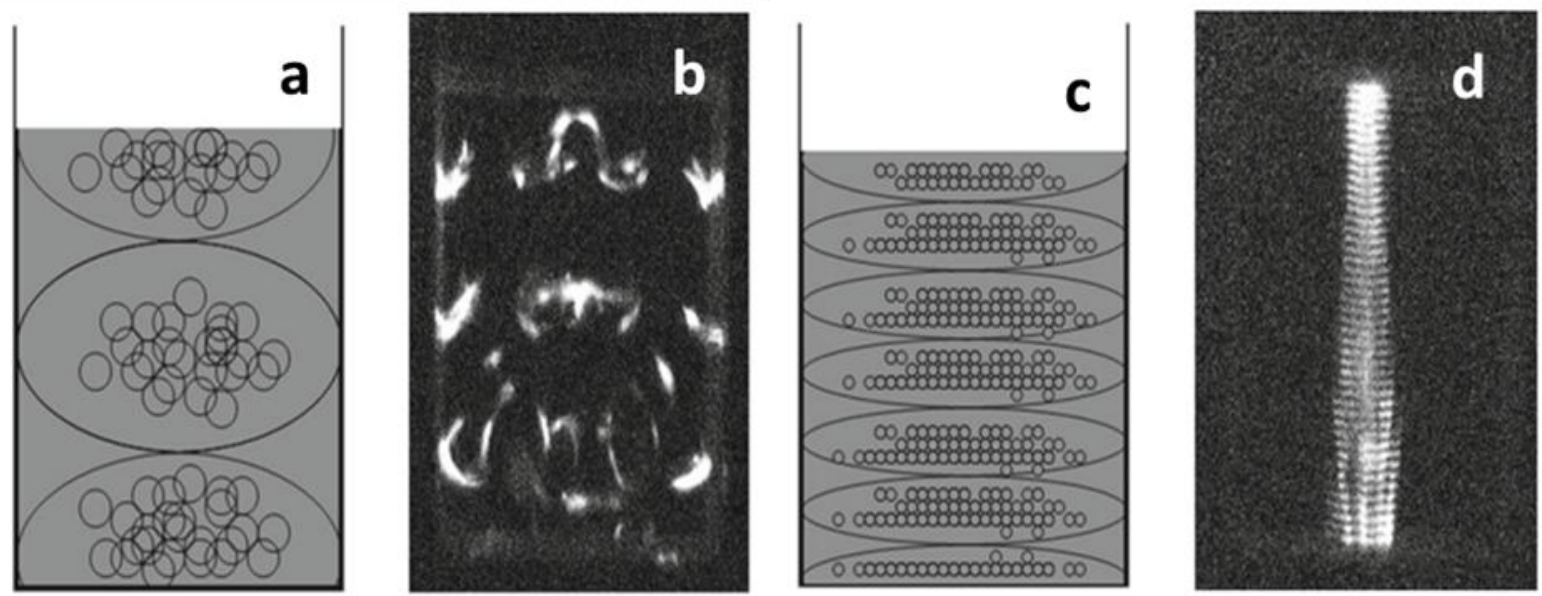

Figure 10: (a) and (c) schematic representation of the standing wave leading to increase in the number of bubbles with increasing frequency, (b) and (c) Images of Sonoluminescence profile at 37 and 440 kHz respectively (Reprinted with permission from Springer [19]; Copyright (2016)).

Figure 16 represents the $\mathrm{OH}$ radical yield as a function of sonication time obtained by sonicating water for different frequencies $(20 \mathrm{kHz}, 358 \mathrm{kHz}$ and $1062 \mathrm{kHz})$ at power of 0.90 $\mathrm{W} / \mathrm{cm}^{2}$ [110]. The amount of $\mathrm{OH}$ radicals produced was highest at $358 \mathrm{kHz}$ whereas decrease was observed when the frequency was increased to $1062 \mathrm{kHz}$.

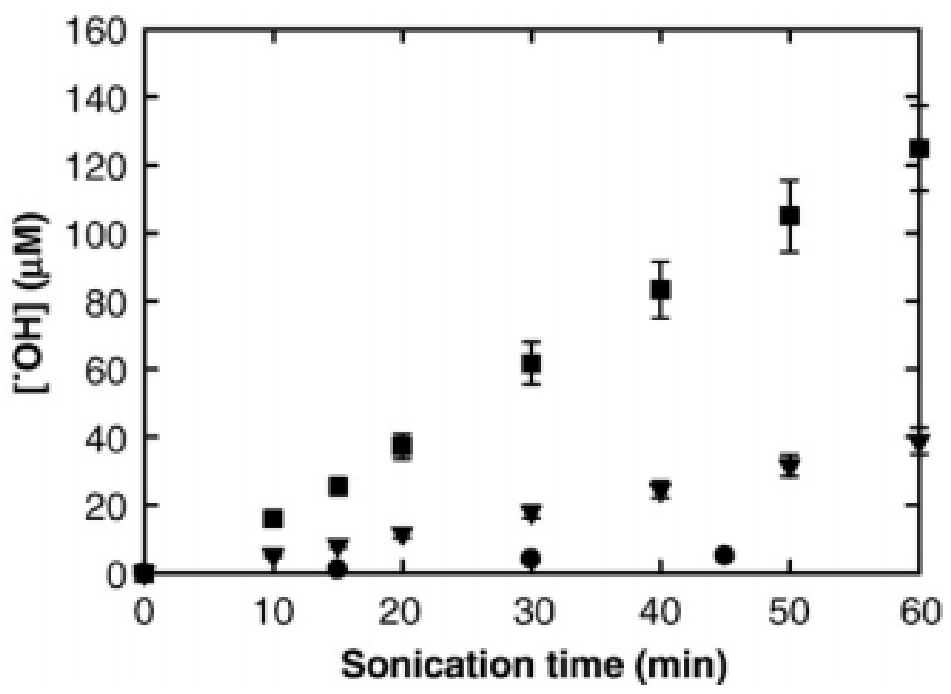

Figure 11: $\mathrm{OH}$ radicals yield as a function of sonication time for different ultrasonic frequencies ($358 \mathrm{kHz}, \boldsymbol{\nabla} 1062 \mathrm{kHz}, \bullet 20 \mathrm{kHz}$ ) at $0.90 \mathrm{~W} \mathrm{~cm}-2$ (Reprinted with permission from Elsevier [110];

Copyright (2008)). 
This is due to a relatively lower bubble temperature generated at higher frequency and a lower amount of water vapour that could evaporate into a bubble during the expansion phase [110], as shown in Figure 17 by theoretical calculations.

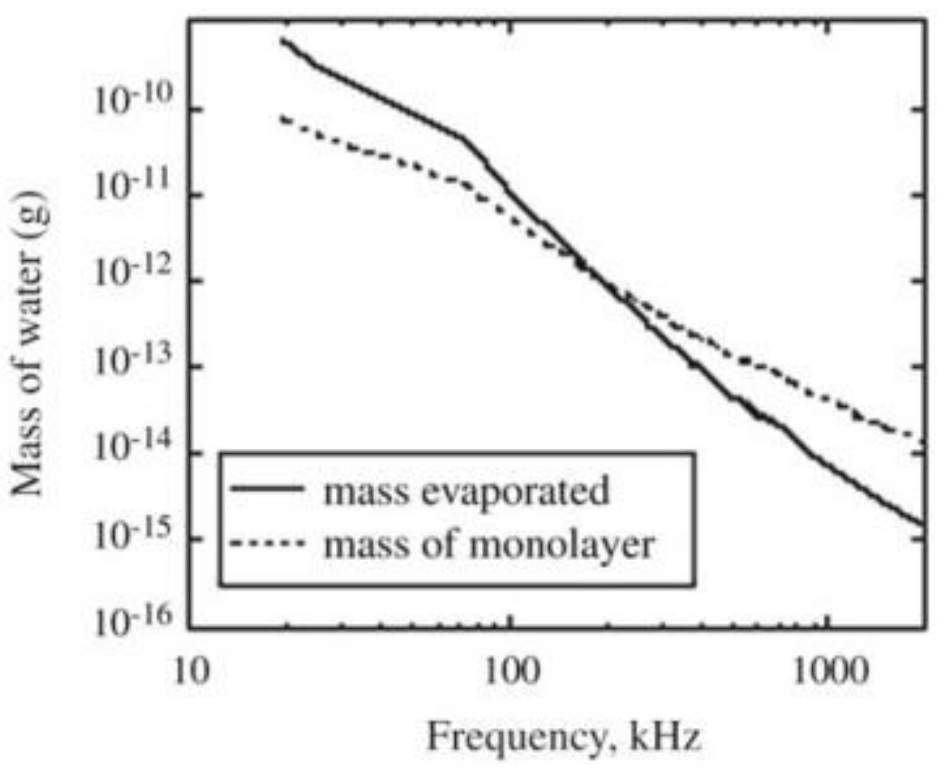

Figure 17: Mass of water evaporated from bubble surface during a single expansion phase at various frequencies (Reprinted with permission from Springer [19]; Copyright (2016)).

Using the resonance radius of the bubbles at each frequency, the amount of water molecules in a monolayer on the surface of bubbles could be calculated [110]. As for the evaporation process, a finite time is required. From the time required for evaporation and expansion cycle and the number of molecules at the interface, it can be seen that the mass that evaporates exceeds the amount present in a monolayer on the bubble surface at lower frequencies. At higher frequencies, the amount that could evaporate is less than a monolayer, which is due to very short expansion time available during bubble oscillations. Though a surge in bubble population occurs at higher frequency, the size of bubble reduces leading to a decrease in the bubble temperature hence the radical yield. Thus, a combination of lower bubble temperature and lower amount of water vapour present inside a collapsing bubble is responsible for a decrease in sonochemical efficiency at very high frequencies.

\subsection{Summary}

This chapter has provided an overview of the basics and fundamentals of sonochemistry including the dynamics of bubble motion, growth and collapse as well as different physical and chemical effects generated after the bubble collapse. The primary and secondary radicals and physical effects such microjetting, microstreaming, shear forces and the shock waves 
generated during acoustic cavitation have been used in material synthesis, sonochemical degradation of pollutants, mass transfer enhancement, electrochemistry, food technology, phase separation, alteration of enzyme activity and removal of deposits and biofilms [108113], which will be discussed in various chapters of this book. 


\section{References:}

1. Ashokkumar M, Mason TJ (2007) Sonochemistry. Kirk-Othmer Encyclopedia of Chemical Technology

2. Duckhouse H, Mason T, Phull S, Lorimer J (2004) The effect of sonication on microbial disinfection using hypochlorite. Ultrason Sonochem 11:173-176

3. Ferrara K, Pollard R, Borden M (2007) Ultrasound microbubble contrast agents: fundamentals and application to gene and drug delivery. Biomed Eng $9: 415-447$

4. Thornycroft JI, (1895) Barnaby SW Torpedo-boat destroyers. In: Minutes of the Proceedings of the Institution of Civil Engineers, Thomas Telford-ICE Virtual Library, 51-69

5. Rayleigh L (1917) VIII. On the pressure developed in a liquid during the collapse of a spherical cavity. Lond Edinb Dubl Phil Mag 34:94-98

6. Brohult S (1937) Splitting of the haemocyanin molecule by ultrasonic waves. Nature 140:805

7. Schultes, H.F.a.H.,( 1935) Luminescenz im Ultraschallbeschickten Wasser. Z. Phys. Chem, 27: 421

8. Weiss, J. (1944) Radiochemistry of aqueous solutions. Nature,153: 48-50

9. Parke A, Taylor D (1956) . The chemical action of ultrasonic waves. J Chem Phys (Resumed):4442-4450

10. Schulz R, Henglein A (1953) Notizen: Über den Nachweis von freien Radikalen, die unter dem Einfluß von Ultraschallwellen gebildet werden, mit Hilfe von Radikal-Kettenpolymerisation und Diphenyl-pikryl-hydrazyl. Zeitschrift für Naturforschung B 8:160-161

11. Noltingk BE, Neppiras EA (1950) Cavitation produced by ultrasonics. Proc Phys Soc Sect B 63:674

12. Makino K, Mossoba MM, Riesz P (1983) Chemical effects of ultrasound on aqueous solutions. Formation of hydroxyl radicals and hydrogen atoms. J Phys Chem 87:1369-1377

13. Henglein A (1987) Sonochemistry: historical developments and modern aspects. Ultrasonics 25:6-16

14. Leighton T (2012) The acoustic bubble. Academic press

15. Lorimer JP, Mason TJ (1987) Sonochemistry. Part 1-the physical aspects. Chem Soc Rev $16: 239-274$

16. Mason T, Paniwnyk L, Lorimer J (1996) The uses of ultrasound in food technology. Ultrason Sonochem 3:S253-S26

17. Mason TJ, Lorimer JP (1989) An introduction to sonochemistry. Endeavour 13:123-128

18. Leong T, Wu S, Kentish S, Ashokkumar M (2010) Growth of bubbles by rectified diffusion in aqueous surfactant solutions. J Phys Chem C 114:20141-20145

19. Ashokkumar M (2016) Ultrasonic Synthesis of Functional Materials. In: Ultrasonic Synthesis of Functional Materials. Springer, 17-40

20. Crum LA (1982) Nucleation and stabilization of microbubbles in liquids. Appl Sci Res 38 :101115

21. Ashokkumar M (2010) Theoretical and experimental sonochemistry involving inorganic systems. Springer Science \& Business Media

22. Yount, D.E. (1979) Skins of varying permeability: a stabilization mechanism for gas cavitation nuclei. J. Acoust. Soc. Am. 65:1429-1439.

23. Lim M, Ashokkumar M, Son Y (2014) The effects of liquid height/volume, initial concentration of reactant and acoustic power on sonochemical oxidation. Ultrason Sonochem 21:1988-1993

24. Crum L (1984) Acoustic cavitation series: part five rectified diffusion. Ultrasonics 22:215-223

25. Yasui K, Tuziuti T, Kanematsu W, Kato K (2016) Dynamic equilibrium model for a bulk nanobubble and a microbubble partly covered with hydrophobic material. Langmuir

26. Yasui, K (2002) Influence of ultrasonic frequency on multibubble sonoluminescence. J. Acoust. Soc. Am. 112: 1405-1413.

27. Bremond N, Arora M, Dammer SM, Lohse D (2006) Interaction of cavitation bubbles on a wall. Phys Fluids $18: 121505$ 
28. Yount D, Gillary E, Hoffman D (1984) A microscopic investigation of bubble formation nuclei. J Acoust Soc Am 76:1511-1521

29. Calvisi ML, Lindau O, Blake JR, Szeri AJ (2007) Shape stability and violent collapse of microbubbles in acoustic traveling waves. Phys Fluids (1994-present) 19:047101

30. Wang W, Chen W, Lu M, Wei R (2003) Bubble oscillations driven by aspherical ultrasound in liquid. J Acoust Soc Am 114:1898-1904

31. Plesset M (1949) The dynamics of cavitation bubbles. J Appl Mech 16:277-282

32. Poritsky $\mathrm{p}$ (1952) The collapse or growth of a spherical bubble or cavity in a viscous fluid. proceedings of the 1st US National Congress in Applied Mathematics :813

33. Tomita Y, Shima A (1986) Mechanisms of impulsive pressure generation and damage pit formation by bubble collapse. J Fluid Mech 169:535-564

34. Yasui K (1998) Effect of non-equilibrium evaporation and condensation on bubble dynamics near the sonoluminescence threshold. Ultrasonics 36:575-580

35. Grieser F, Ashokkumar M (2006) Sonochemical synthesis of inorganic and organic colloids. Colloids and Colloid Assemblies: Synthesis, Modification, Organization and Utilization of Colloid Particles: 1842.

36. Hsieh DY, Plesset MS (1961) Theory of rectified diffusion of mass into gas bubbles. J Acoust Soc Am 33:206-215

37. Eller A, Flynn H (1965) Rectified diffusion during nonlinear pulsations of cavitation bubbles. J Acoust Soc Am 37:493-503

38. Fyrillas MM, Szeri AJ (1996) Surfactant dynamics and rectified diffusion of microbubbles. J Fluid Mech 311:361-3781

39. Lee J, Kentish S, Ashokkumar M (2005) Effect of surfactants on the rate of growth of an air bubble by rectified diffusion. J Phys Chem B $109: 14595-14598$

40. Vinodgopal K, He Y, Ashokkumar M, Grieser F (2006) Sonochemically prepared platinumruthenium bimetallic nanoparticles. J Phys Chem B 110:3849-3852

41. Anandan S, Grieser F, Ashokkumar M (2008) Sonochemical synthesis of $\mathrm{Au}-\mathrm{Ag}$ core- shell bimetallic nanoparticles. J Phys Chem C 112:15102-15105

42. Kumar PSS, Manivel A, Anandan S, Zhou M, Grieser F, Ashokkumar M (2010) Sonochemical synthesis and characterization of gold-ruthenium bimetallic nanoparticles. Colloids Surf A Physicochem Eng Asp 356 :140-144

43. Lee J, Ashokkumar M, Kentish S, Grieser F (2005) Determination of the size distribution of sonoluminescence bubbles in a pulsed acoustic field. J Am Chem Soc 127:16810-16811

44. Brotchie A, Grieser F, Ashokkumar M (2009) Effect of power and frequency on bubble-size distributions in acoustic cavitation. Phys Rev lett 102:084302

45. Burdin F, Tsochatzidis N, Guiraud P, Wilhelm A, Delmas H (1999) Characterisation of the acoustic cavitation cloud by two laser techniques. Ultrason Sonochem $6: 43-51$

46. Chen W-S, Matula TJ, Crum LA (2002) The disappearance of ultrasound contrast bubbles: observations of bubble dissolution and cavitation nucleation. Ultrasound Med Biol 28:793-803

47. Tsochatzidis N, Guiraud P, Wilhelm A, Delmas H (2001) Determination of velocity, size and concentration of ultrasonic cavitation bubbles by the phase-Doppler technique. Chem Eng Sci 56:1831-1840

48. Yasui K, Tuziuti T, Kozuka T, Towata A, Iida Y (2007) Relationship between the bubble temperature and main oxidant created inside an air bubble under ultrasound. J Chem Phys 127:154502-154502

49. Merouani S, Hamdaoui O, Rezgui Y, Guemini M (2014) Theoretical estimation of the temperature and pressure within collapsing acoustical bubbles. Ultrason Sonochem 21:53-59

50. Misik V, Miyoshi N, Riesz P (1995) EPR spin-trapping study of the sonolysis of H2O/D2O mixtures: probing the temperatures of cavitation regions. J Phys Chem 99:3605-3611

51. Suslick KS, Hammerton DA, Cline RE (1986) Sonochemical hot spot. J Am Chem Soc 108:5641-5642 
52. Hart EJ, Fischer C-H, Henglein A (1990) Sonolysis of hydrocarbons in aqueous solution. Int J Radiat Appl Instrum C Radiat Phys Chem 36:511-516

53. Sonntag C (1999) Sonolysis of tert-butyl alcohol in aqueous solution. J Chem Soc, Perkin Transactions 2:1129-1136

54. Rae J, Ashokkumar M, Eulaerts O, von Sonntag C, Reisse J, Grieser F (2005) Estimation of ultrasound induced cavitation bubble temperatures in aqueous solutions. Ultrason Sonochem 12:325-329

55. Ciawi E, Rae J, Ashokkumar M, Grieser F (2006) Determination of temperatures within acoustically generated bubbles in aqueous solutions at different ultrasound frequencies. J Phys Chem B $110: 13656-13660$

56. Crum L (1994) Sonoluminescence, sonochemistry, and sonophysics. J Acoust Soc Am 95 :559562

57. Mason TJ, Peters D (2002) Practical sonochemistry: Power ultrasound uses and applications. Woodhead Publishing

58. Ashokkumar M, Lee J, Kentish S, Grieser F (2007) Bubbles in an acoustic field: an overview. Ultrason Sonochem 14:470-475.

59. Trillat NMaJJ (1933) Action des ultrasons sur les plaques photographiques. CR Acad Sci Paris 196:858

60. Griffing V, Sette D (1955) Luminescence produced as a result of intense ultrasonic waves. J Phys Chem 23:503-509

61. Suslick KS, Crum LA (1998) Sonochemistry and sonoluminescence. Wiley-Interscience: New York

62. Yasui K (1999) Mechanism of single-bubble sonoluminescence. Phys Rev E 60:1754

63. An Y (2006) Mechanism of single-bubble sonoluminescence. Phys Rev E 74: 026304.

64. JARMAN P (1958) SONOLUMINESCENCE. Sci Prog 46 :632-639

65. Crum L, Walton A, Mortimer A, Dyson M, Crawford D, Gaitan D (1987) Free radical production in amniotic fluid and blood plasma by medical ultrasound. J Utras Med 6 :643-647

66. Finch R (1963) Sonoluminescence. Ultrasonics 1:87-98

67. Weissler A (1953) Sonochemistry: the production of chemical changes with sound waves. J Acoust Soc Am 25:651-657

68. Chendke P, Fogler H (1983) Sonoluminescence and sonochemical reactions of aqueous carbon tetrachloride solutions. J Phys chem 87:1362-1369

69. Chambers LA (1937) The emission of visible light from cavitated liquids. J Chem Phys 5:290292

70. Wu C, Roberts PH (1993) Shock-wave propagation in a sonoluminescing gas bubble. Phys Rev Lett 70:3424

71. Moss WC, Clarke DB, White JW, Young DA (1994) Hydrodynamic simulations of bubble collapse and picosecond sonoluminescence. Phys Fluids 6:2979-2985

72. Kondić L, Gersten JI, Yuan C (1995) Theoretical studies of sonoluminescence radiation: Radiative transfer and parametric dependence. Phys Rev E $52: 4976$

73. Kwak H-Y, Na JH (1996) Hydrodynamic solutions for a sonoluminescing gas bubble. Phys Rev Lett 77:4454

74. Yasui K (1997) Alternative model of single-bubble sonoluminescence. Phys Rev E 56:6750

75. Yasui K (1999) Single-bubble and multibubble sonoluminescence. Phys Rev Lett 83:4297

76. Hatanaka S-i, Mitome H, Yasui K, Hayashi S (2002) Single-bubble sonochemiluminescence in aqueous luminol solutions. J Am Chem Soc 124:10250-10251

77. Ashokkumar M (2011) The characterization of acoustic cavitation bubbles-an overview. Ultrason sonochem 18:864-872

78. Ashokkumar M, Lee J, Iida Y, Yasui K, Kozuka T, Tuziuti T, Towata A (2010) Spatial distribution of acoustic cavitation bubbles at different ultrasound frequencies. ChemPhysChem 11:1680-1684

79. Sunartio D, Yasui K, Tuziuti T, Kozuka T, Iida Y, Ashokkumar M, Grieser F (2007) Correlation between $\mathrm{Na}^{*}$ emission and "chemically active" acoustic cavitation bubbles. ChemPhysChem 8:2331-2335 
80. Mišík V, Riesz P (1996) EPR study of free radicals induced by ultrasound in organic liquids II. Probing the temperatures of cavitation regions. Ultrason Sonochem 3:25-37

81. Mišík V, Riesz P (1996) Recent applications of EPR and spin trapping to sonochemical studies of organic liquids and aqueous solutions. Ultrason Sonochem 3:S173-S186

82. Mason T, Lorimer J, Bates D, Zhao Y (1994) Dosimetry in sonochemistry: the use of aqueous terephthalate ion as a fluorescence monitor. Ultrason Sonochem 1:S91-S95

83. Ashokkumar M, Niblett T, Tantiongco L, Grieser F (2003) Sonochemical degradation of sodium dodecylbenzene sulfonate in aqueous solutions. Aust J hem 56 :1045-1049

84. Ashokkumar M, Grieser F (2005) A comparison between multibubble sonoluminescence intensity and the temperature within cavitation bubbles. J Am Chem Soc $127: 5326-5327$

85. Hatanaka S-i, Yasui K, Kozuka T, Tuziuti T, Mitome H (2002) Influence of bubble clustering on multibubble sonoluminescence. Ultrasonics 40:655-660

86. Kanthale P, Ashokkumar M, Grieser F (2008) Sonoluminescence, sonochemistry (H 2 O 2 yield) and bubble dynamics: frequency and power effects. Ultrason Sonochem 15:143-150

87. Yasui K (2001) Temperature in multibubble sonoluminescence. J Chem Phys 115:2893-2896

88. Weninger, K., C. Camara, and S. Putterman (2000) Observation of bubble dynamics within luminescent cavitation clouds: sonoluminescence at the nano-scale. Phys Rev E, 63: 016310.

89. Yasui K, Tuziuti T, Sivakumar M, Iida Y (2005) Theoretical study of single-bubble sonochemistry. J Chem Phys 122:224706

90. Didenko YT, Suslick KS (2002) The energy efficiency of formation of photons, radicals and ions during single-bubble cavitation. Nature 418 (6896):394-397

91. Matula TJ, Crum LA (1998) Evidence for gas exchange in single-bubble sonoluminescence. Phys Rev Lett 80:865

92. Kruus P (2000) Sonochemical formation of nitrate and nitrite in water. Ultrason Sono 7:109113

93. Koda S, Tanaka K, Sakamoto H, Matsuoka T, Nomura H (2004) Sonochemical efficiency during single-bubble cavitation in water. J Phys Chem A 108:11609-11612

94. Yasui K, Tuziuti T, Iida Y, Mitome H (2003) Theoretical study of the ambient-pressure dependence of sonochemical reactions. J Chem Phys 119:346-356

95. Vazquez G, Camara C, Putterman S, Weninger K (2001) Sonoluminescence: nature's smallest blackbody. Opt Lett 26:575-577

96. Tuziuti T, Yasui K, Sivakumar M, Iida Y, Miyoshi N (2005) Correlation between acoustic cavitation noise and yield enhancement of sonochemical reaction by particle addition. J Phys Chem A 109:4869-4872

97. Matula TJ, Roy RA, Mourad PD, McNamara III WB, Suslick KS (1995) Comparison of multibubble and single-bubble sonoluminescence spectra. Phys Rev Lett 75:2602

98. Mettin R, Akhatov I, Parlitz U, Ohl C, Lauterborn W (1997) Bjerknes forces between small cavitation bubbles in a strong acoustic field. Phys Rev E 56:2924

99. Lucien E, Greer A (2001) Electrophilic oxidant produced in the photodeoxygenation of 1, 2benzodiphenylene sulfoxide. J Org Chem 66:4576-4579

100. Brown WG, Hart EJ (1972) The oxygen atom: A primary species in irradiated water. Radiat Res 51:249-253

101. Sauer Jr MC, Brown WG, Hart EJ (1984) Oxygen (3P) atom formation by the photolysis of hydrogen peroxide in alkaline aqueous solutions. J Phys Chem 88:1398-1400

102. Hart EJ, Henglein A (1985) Free radical and free atom reactions in the sonolysis of aqueous iodide and formate solutions. J Phys Chem 89:4342-4347

103. Thomas KB, Greer A (2003) Gauging the significance of atomic oxygen [O (3P)] in sulfoxide photochemistry. A method for hydrocarbon oxidation. J Org Chem 68:1886-1891

104. Yasui K (2001) Effect of liquid temperature on sonoluminescence. Phys Rev E 64:016310

105. Toegel R, Gompf B, Pecha R, Lohse D (2000) Does water vapor prevent upscaling sonoluminescence? Phys Rev Lett $85: 3165$

106. Yasui K, Tuziuti T, Iida Y (2004) Optimum bubble temperature for the sonochemical production of oxidants. Ultrasonics 42:579-584 
107. Beckett MA, Hua I (2001) Impact of ultrasonic frequency on aqueous sonoluminescence and sonochemistry.J Phys Chem A 105:3796-3802

108. Capocelli M, Joyce E, Lancia A, Mason TJ, Musmarra D, Prisciandaro M (2012) Sonochemical degradation of estradiols: Incidence of ultrasonic frequency. Chem Eng J 210:9-17

109. Petrier C, Jeunet A, Luche JL, Reverdy G (1992) Unexpected frequency effects on the rate of oxidative processes induced by ultrasound. J Am Chem Soc 114:3148-3150

110. Ashokkumar M, Sunartio D, Kentish S, Mawson R, Simons L, Vilkhu K, Versteeg CK (2008) Modification of food ingredients by ultrasound to improve functionality: a preliminary study on a model system. Innov Food Sci Emerg 9:155-160

108. Shanmugam A, Chandrapala J, Ashokkumar M (2012) The effect of ultrasound on the physical and functional properties of skim milk.Innov Food Sci Emer 16:251-258

109. Ashokkumar M, Lee J, Zisu B, Bhaskarcharya R, Palmer M, Kentish S (2009) Hot topic: Sonication increases the heat stability of whey proteins. J Dairy Sci 92 :5353-5356.

110. Chandrapala J, Zisu B, Palmer M, Kentish S, Ashokkumar M (2011) Effects of ultrasound on the thermal and structural characteristics of proteins in reconstituted whey protein concentrate. Ultrason Sonochem 18:951-957

111. Price GJ (1996) Ultrasonically enhanced polymer synthesis. Ultrason Sonochem 3:S229-S238

112. Bhangu SK, Ashokkumar M, Lee J (2016) Ultrasound Assisted Crystallization of Paracetamol: Crystal Size Distribution and Polymorph Control. Crys Growth Des 16:1934-1941

113. Mason TJ (2003) Sonochemistry and sonoprocessing: the link, the trends and (probably) the future. Ultrason Sonochem 10:175-179 


\section{University Library}

\section{- M M I N E R VA A gateway to Melbourne's research publications}

Minerva Access is the Institutional Repository of The University of Melbourne

Author/s:

Bhangu, SK;Ashokkumar, M

Title:

Theory of Sonochemistry

Date:

2016-08-01

Citation:

Bhangu, S. K. \& Ashokkumar, M. (2016). Theory of Sonochemistry. TOPICS IN CURRENT CHEMISTRY, 374 (4), https://doi.org/10.1007/s41061-016-0054-y.

Persistent Link:

http://hdl.handle.net/11343/282592 